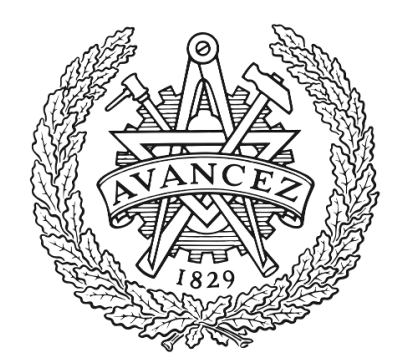

\title{
CHALMERS
}

UNIVERSITY OF TECHNOLOGY

\section{Oxidation Level and Glycidyl Ether Structure Determine Thermal Processability and Thermomechanical Properties of Arabinoxylan-Derived}

Downloaded from: https://research.chalmers.se, 2023-04-26 09:03 UTC

Citation for the original published paper (version of record):

Deralia, P., Maire Du Poset, A., Lund, A. et al (2021). Oxidation Level and Glycidyl Ether Structure Determine Thermal Processability and

Thermomechanical Properties of Arabinoxylan-Derived Thermoplastics. ACS Applied Bio Materials, 4(4): 3133-3144. http://dx.doi.org/10.1021/acsabm.0c01550

N.B. When citing this work, cite the original published paper. 


\title{
Oxidation Level and Glycidyl Ether Structure Determine Thermal Processability and Thermomechanical Properties of Arabinoxylan- Derived Thermoplastics
}

\author{
Parveen Kumar Deralia,* Aline Maire du Poset, Anja Lund, Anette Larsson, Anna Ström, \\ and Gunnar Westman*
}

Cite This: https://dx.doi.org/10.1021/acsabm.0c01550

Read Online

\section{ACCESS}

Џ Metrics \& More

回国 Article Recommendations

Supporting Information

ABSTRACT: Developing flexible, stretchable, and thermally processable materials for packaging and stretchable electronic applications from polysaccharide-based polymers contributes to the smooth transition of the fossil-based economy to the circular bioeconomy. We present arabinoxylan (AX)-based thermoplastics obtained by ring-opening oxidation and subsequent reduction (dA-AX) combined with hydrophobization with three different glycidyl ethers [ $n$-butyl (BuGE), isopropyl (iPrGE), and 2-ethyl hexyl (EtHGE) glycidyl ether]. We also investigate the relationship between structural composition, thermal processing, and thermomechanical properties. BuGE- and iPrGEetherified dA-AXs showed glass-transition temperatures $\left(T_{g}\right)$ far below their degradation temperatures and gave thermoplastic materials when

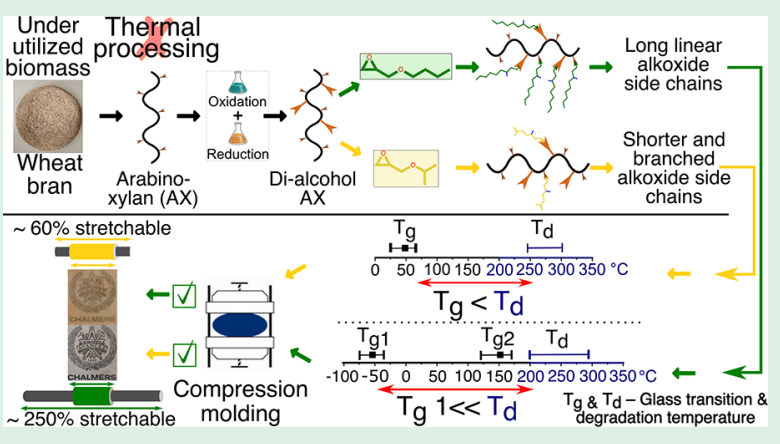
compression-molded at $140{ }^{\circ} \mathrm{C}$. The BuGE $(3 \mathrm{~mol})$-etherified dA-AX films at 19 and $31 \%$ oxidation levels show $244 \%( \pm 42)$ and $267 \%( \pm 72)$ elongation, respectively. In contrast, $i$ PrGE-dA-AX samples with shorter and branched terminals in the side chains had a maximum of $60 \%( \pm 19)$ elongation. No studies have reported such superior elongation of AX thermoplastic films and its relationship with molar substitution and $T_{\mathrm{g}}$. These findings have implications on the strategic development of chemical modification routes using commercial polymer processing technologies and on fine-tuning structures and properties when specific polysaccharidebased polymers are used to engineer bio-based products for film, packaging, and substrates for stretchable electronic applications.

KEYWORDS: arabinoxylan, biomass-wheat bran, epoxide ring-opening etherification, oxidation, renewable resource, thermal processability, thermoplastic film

\section{INTRODUCTION}

Sustainable resource supply and its efficient use for materials and chemicals are central to the success of the bioeconomy. Polysaccharides are promising candidates for this purpose owing to their renewability, abundance, and functionality. Among polysaccharides, arabinoxylans (AXs) are heteroxylans present in cereal grains. Their backbones are composed of $\beta$ 1,4-linked xylopyranosyl residues that are substituted with arabinofuranosyl residues and less often with arabino-linked feruloyl esters and glucuronosyl residues, depending on the biological origin. ${ }^{1,2}$ The extraction method also changes the substitution degree and pattern of the polymers and imparts differential reactivity and physical properties to them.

Material scientists are interested in exploiting structural functionality and physical properties of polysaccharides for antioxidants $^{3}$ in multifunctional food applications; for films, coatings, emulsions, ${ }^{4}$ additives, ${ }^{5}$ and hydrogels in material applications; and for stretchable substrates in electronic devices. ${ }^{6-9}$ Using AX in films for packaging and stretchable electronics is restricted by brittleness and poor stretchability.
Organic solvents can dissolve and plasticize biopolymers by reducing inter- and intramolecular $\mathrm{H}$ bonding and so enable processing. However, upscaling of solvent processing for materials is unattractive because of the long processing time and bulk solvent need. Therefore, commercial processing techniques are required to harness the potentials of polysaccharides to superior materials. Conversion of polysaccharides to materials is challenging because of poor thermal processability and inaccessible melt phase, owing to higher melting $\left(T_{\mathrm{m}}\right)$ and glass-transition temperatures $\left(T_{\mathrm{g}}\right)$ compared to their degradation temperature $\left(T_{\mathrm{d}}\right) \cdot^{10-12}$

Using external plasticizers, e.g., nonvolatile glycerol, sorbitol, water, etc., and chemical modification are common strategies

Received: November 29, 2020

Accepted: February 16, 2021 
used to make polysaccharides thermoplastic. External plasticizers, fillers, and stabilizers have shown to enhance the processability, mechanical properties, and environmental stability of polymers. ${ }^{13,14}$ For example, external plasticizers enabled thermal processability in $\operatorname{starch}^{15,16}$ and cellulose acetate. ${ }^{17}$ However, plasticizers can also cause unwanted side effects, e.g., weak mechanical properties, plasticizer migration, recrystallization over time, etc. ${ }^{13,18}$ Many studies had focused on chemical modification of starch, ${ }^{19-23}$ proteins, ${ }^{24,25}$ and cellulose acetate $e^{26-28}$ to improve processability and product performance. Despite this progress, the chemical modification strategy is less investigated for thermoplastic arabinoxylans in contrast with cellulose and starch. Thus, it is desirable to develop more means within this strategy.

Stronger intra- and intermolecular interactions influence thermal processability and make AX difficult to process via mature polymer thermal processing techniques such as compression molding, injection molding, and extrusion. The glass-transition temperature $\left(T_{\mathrm{g}}\right)$ depends on an interplay of intermolecular forces, ${ }^{29,30}$ chain stiffness, ${ }^{31}$ pendant groups, $^{32,33}$ and molecular weight. ${ }^{34}$ Tuning these interactions/factors by chemical modification leads to a decrease in $T_{\mathrm{g}}$ below the degradation temperature. In this context, it has been shown that the $T_{\mathrm{g}}$ of xylan decreased to 70,124 , and $134{ }^{\circ} \mathrm{C}$ upon derivatization with propylene oxide ${ }^{33}$ and butyl glycidyl ether $^{35}$ and upon oxidation, ${ }^{36}$ respectively. The $T_{\mathrm{g}}$ of glucomannan was also shown to reduce upon acylation, and glucomannan acylates could be thermoprocessed. ${ }^{12}$

A recent investigation showed that grafting of $n$-butyl glycidyl ether (BuGE) on $\mathrm{OH}$ groups of periodate (PI) oxidized and reduced arabinoxylan (AX) and ring-opening polymerization of BuGE monomers on sequentially periodateoxidized and -reduced $\mathrm{AX}$ as the initiation site of polymerization results in a thermally processable stretchable thermoplastic material. ${ }^{34}$ Xylan was made hydrophobic and thermoplastic via grafting from polymerization with octadecyl acrylate to replace hydroxyl groups attached to its backbone. This modified xylan was used as a renewable additive in a poly $(\varepsilon$ caprolactone) (PCL) biocomposite. ${ }^{37}$ Modification of xylan by incorporating short poly( $\varepsilon$-caprolactone) (PCL) tails also improves the thermoprocessability and thermomechanical properties. $^{38,39}$ Despite these studies, there remains to explore (a) how thermomechanical properties may relate to the structural composition (molar substitution (MS)) and thermal processing of the derivatized polymer, (b) whether other reactants can enable thermal processability and how their structure may relate to thermal processing, and (c) whether lowering $T_{\mathrm{g}}$ enables thermal processing. We need further research advancements in the modification strategy to make polysaccharides thermally processable thermoplastics and get tunable physiochemical properties. Chemical modification of polysaccharides using ester and glycidyl ether was shown to affect polymerization and processability. ${ }^{34,35,40,41}$ A variety of factors, such as the structure and composition of native AX and oxidation level, can contribute to the differential properties and processability $^{32-34}$ and are included in this study along with different etherification agents. Wheat bran, a cheap byproduct of the cereal industry, is used for animal feed. AX was extracted from wheat bran because (a) wheat bean is available in abundance, making it a potential feedstock in cereal biorefineries, and (b) the extracted AX is water-soluble. ${ }^{34}$

The focus of this study is to design and synthesize thermally processable AX with different physical properties and to investigate the possibility of using different glycidyl ethers (etherification agents) after activating $\mathrm{AX}$ through successive periodate oxidation (at two levels) and reduction to make AX melt-processable. We do this to probe the correlation between properties and structures. Two oxidation levels were used to adjust the number of open carbohydrate units. Three etherification agents, $n$-butyl (BuGE), isopropyl (iPrGE), and 2-ethyl hexyl (EtHGE) glycidyl ether, were judiciously selected that vary in structure and chemical and physical properties (Table S1) and were varied in amount to shield and to use the reactive $\mathrm{OH}$ groups as coupling points on $\mathrm{AX}$. This will help in adjusting intermolecular forces and molecular weights. This broad experimental design offers the possibility of tuning the properties of the obtained materials. We analyzed the neat and functionalized AXs for structure (infrared (IR) and NMR), chemical composition (high-performance liquid chromatography (HPLC)), and thermal and mechanical properties (differential scanning calorimetry (DSC) for $T_{\mathrm{g}}$, thermogravimetric analysis (TGA), tensile tests) to give information about the correlation between properties and polymer structures.

\section{EXPERIMENTAL SECTION}

Materials. Wheat bran (particle size between 0.5 and $1.4 \mathrm{~mm}$ ) used for extraction of arabinoxylan was provided by Lantmännen $A B$ (Stockholm, Sweden). Chemicals, reagents, enzymes, and solvents were purchased from Sigma-Aldrich (Schnelldorf, Germany) or Fisher Scientific (Sweden) and used without further purification unless stated otherwise. Ethanol was purchased from Solveco AB (Sweden). Distilled water was used throughout. Dialysis tubing (Spectra/Por, MWCO 3500) was from Spectrum Laboratories Inc., CA. The wheat bran composition was determined by the standard National Renewable Energy Laboratory (NREL) method: ${ }^{42}$ glucan $29 \pm 2 \%$, mannan $1 \pm 0 \%$, galactan $1.0 \pm 0 \%$, xylan $15 \pm 1 \%$, arabinan $10 \pm$ $1 \%$, acid-insoluble lignin (AIL) $12 \pm 2 \%$, and ash $5 \% \pm 0.0$ (rest $27 \%$ ). Arabinoxylan (AX) was extracted from wheat bran according to the earlier literature ${ }^{43}$ with slight modifications, and the extraction procedure is on Page S2 in the Supporting Information. Figure 1 illustrates the experimental steps used in the study.

Syntheses of Activated Arabinoxylan Ethers. Syntheses of Di-Alcohol/Activated Arabinoxylans $(d A-A X)$. Activated AX (dA$\mathrm{AX})$ was synthesized from $\mathrm{AX}$ through successive oxidative and reduction in Step 1 (Figure 2a). The sample codes, synthesis parameters, and characterizations of the activated $\mathrm{AX}$ and activated AX ethers are in Table 1 . Tables S1 and S2 present the details on etherification agents and sample codes.

Periodate Oxidation of Arabinoxylan. Di-aldehyde arabinoxylan (dAl-AX) was prepared according to the reported literature. ${ }^{44,45}$ Briefly, AX (4 g dry basis, $30.30 \mathrm{mmol}$ ) was suspended in $10 \mathrm{~mL}$ of 2propanol and $165 \mathrm{~mL}$ of water, and the mixture was stirred at $50{ }^{\circ} \mathrm{C}$ for $1 \mathrm{~h}$. Different predetermined amounts of sodium meta (Table 1) were dissolved in $25 \mathrm{~mL}$ of water, and the solutions were added to the flask, giving $2 \%$ concentration. The reaction was carried out at room temperature $\left(20^{\circ} \mathrm{C}\right)$ for $14 \mathrm{~h}$ in the dark. The reaction mixture was used in the reduction step.

Reduction of Oxidized Arabinoxylan. A premixed suspension of 2 $\mathrm{g}$ of sodium borohydride $\mathrm{NaBH}_{4}$ (reducing agent) and $0.3 \mathrm{~g}$ of sodium monophosphate $\mathrm{NaH}_{2} \mathrm{PO}_{4}$ (used as a $\mathrm{pH}$ buffer to keep the $\mathrm{pH}$ constant) in $50 \mathrm{~mL}$ of water was added to the reaction mixture from the oxidation step, giving $1.6 \%$ concentration. The reaction was performed at room temperature $\left(20^{\circ} \mathrm{C}\right)$ for $4 \mathrm{~h}$. The product (dAAX) was precipitated in methanol and diethyl ether mix (2:1). The activated AX was separated by centrifugation and then was used for the synthesis of GE-dA-AX.

Syntheses of Activated Arabinoxylan Ethers. The activated AX ethers (GE-dA-AX) were synthesized in Step 2 (Figure 2b) according to the reported literature ${ }^{35}$ with some changes. In brief, the activated AX (dA-AX) from the earlier step was suspended in 60 


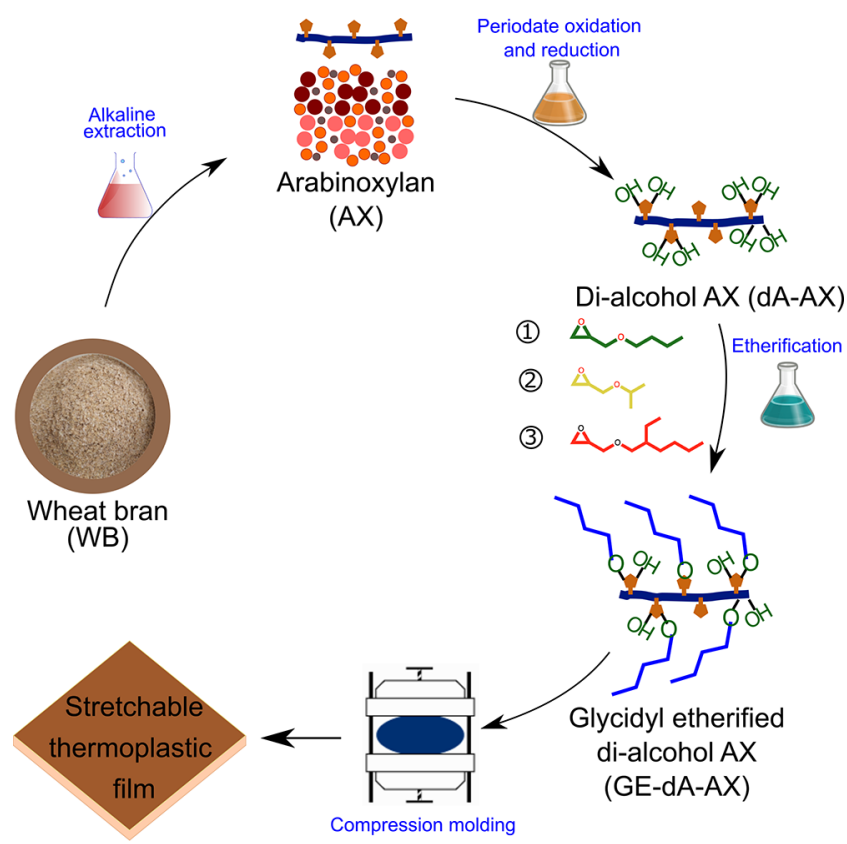

Figure 1. Simple experimental schematic showing the experimental steps. AX was extracted from wheat bran and ring-opening oxidation and subsequent reduction ( $\mathrm{A}-\mathrm{AX})$ was carried out. Finally, three series of arabinoxylan-based thermoplastics were synthesized by introducing (1) BuGE, (2) $i \operatorname{PrGE}$, and (3) EtHGE. These materials were compression-molded.

$\mathrm{mL}$ of $\mathrm{H}_{2} \mathrm{O}$ and the mixture was stirred at $50{ }^{\circ} \mathrm{C}$ for $1 \mathrm{~h}$. Different amounts of $\mathrm{NaOH}$ (Table 1) were dissolved in $45 \mathrm{~mL}$ of water. The aqueous $\mathrm{NaOH}$ solution was added to the flask, and the mixture was stirred at room temperature $\left(20^{\circ} \mathrm{C}\right)$ for $1 \mathrm{~h}$. A predetermined amount of glycidyl ethers was added dropwise over $30 \mathrm{~min}$. The reaction was carried out at $45^{\circ} \mathrm{C}$ for $16 \mathrm{~h}$. Then, the mixture was cooled down and neutralized to $\mathrm{pH} 7.0$ with $2 \mathrm{M} \mathrm{CH} \mathrm{CH}_{3} \mathrm{COOH}$. The BuGE-dA-AX product was separated by centrifugation (while the $i \operatorname{PrGE}-\mathrm{dA}-\mathrm{AX}$ and EtHGE-dA-AX products were first precipitated in methanol and diethyl ether mix (1:0.7) and later separated by centrifugation) and then dried under vacuum at room temperature for $14 \mathrm{~h}$. The product yields are given in Table S3.

Film Fabrication. Compression molding or solvent casting was used to fabricate films from neat $\mathrm{AX}$ and activated $\mathrm{AX}$ ethers. The processing method's details are provided in Table S3.

Compression Molding. The GE-dA-AX samples were cut into small pieces to get homogenous melt and compression-molded into films using molds of $80 \times 80 \times 0.5$ or $50 \times 50 \times 0.5 \mathrm{~mm}^{3}$ dimension $(L \times W \times T)$ between two metal plates on a manual press set to 150 ${ }^{\circ} \mathrm{C}$ for melting. After melting the sample with no pressure between the plates for $3 \mathrm{~min}$, the sample melt was compression-molded under 50 $\mathrm{kPa}$ pressure at $140{ }^{\circ} \mathrm{C}$ for $3 \mathrm{~min}$ to get films.

Solution Casting. This method is used for making films of the samples that were not compression-moldable. The samples were dissolved either in $\mathrm{H}_{2} \mathrm{O}$ or ethanol-water mix (3:1, ethanol 95\%) at $20 \mathrm{~g} / \mathrm{L}$ and stirred at $50{ }^{\circ} \mathrm{C}$ for $1 \mathrm{~h}$. The solution after cooling was poured into a Petri dish and dried at room temperature.

Characterization. Oxidation Level Measurement. The oxidation level was determined from periodate consumption (eq 1 in the Supporting Information) and sugar content reduction (eq 2 in the Supporting Information). Periodate consumption in the oxidation reaction was determined by a UV-vis method. ${ }^{46}$

Carbohydrate Composition and NMR Spectroscopy. The neat and functionalized AXs were hydrolyzed by two-stage sulfuric acid hydrolysis according to the NREL procedure. ${ }^{42}$ An aliquot $(1 \mathrm{~mL})$ of the hydrolyzed sample was used for carbohydrate analysis, and the rest was neutralized and freeze-dried and then used for NMR analysis. The glycidyl ether substitution was determined by both HPLC and
NMR (eqs 3, 4, and 5 in the Supporting Information). Table S5 contains NMR calculation data.

Carbohydrate Composition. The carbohydrate composition was determined by the two-stage sulfuric acid hydrolysis method according to the NREL procedure. ${ }^{42}$ The solubilized monosaccharides were quantified on a Dionex ICS-4000 high-performance anionexchange chromatography (HPAEC) system equipped with a pulsed amperometric detector (PAD) (Dionex, Sunnyvale, CA) coupled to a Dionex CarboPac PA1 analytical column.

NMR Spectroscopy. NMR spectra were recorded with a Varian MR-400 MHz spectrometer (Agilent Technologies) at $25{ }^{\circ} \mathrm{C}$ on freeze-dried solubilized monosaccharide samples. Approximately, 20 $\mathrm{mg}$ of sample was dissolved in $0.7 \mathrm{~mL}$ of NMR-grade $\mathrm{D}_{2} \mathrm{O}\left(\delta_{\mathrm{H}}=\right.$ 4.79) solvent at $50{ }^{\circ} \mathrm{C}$ for $1 \mathrm{~h}$.

Attenuated Total Reflection-Fourier Transform Infrared (ATRFTIR) Spectroscopy. The FTIR analyses were conducted on a PerkinElmer Frontier FTIR spectrometer (Waltham, MA) in attenuated total reflection (ATR) mode within the spectral range of $4000-400 \mathrm{~cm}^{-1}$ at room temperature. A total of 32 scans were collected at $2 \mathrm{~cm}^{-1}$ resolution on room-temperature-dried samples successively conditioned at $23{ }^{\circ} \mathrm{C}$ and $50 \% \mathrm{RH}$ for $24 \mathrm{~h}$. The spectra were baseline-corrected on Spectrum software, and Origin Pro 2018 was used for plotting.

Gel Permeation Chromatography (GPC). The molecular mass distribution analysis was performed by GPC on a PL-GPC 50 plus integrated system equipped with refractive index (RI) and UV detectors (Polymer Laboratories, Varian Inc.) set at $\lambda=280 \mathrm{~nm}$ and a series-coupled Polar Gel-M column and a guard column $(300 \times 7.5$ $\mathrm{mm}^{2}$ and $50 \times 7.5 \mathrm{~mm}^{2}, 8 \mu \mathrm{m}$ ) using dimethyl sulfoxide (DMSO)/ $\mathrm{LiBr}(10 \mathrm{mM})$ as an eluent $(0.5 \mathrm{~mL} / \mathrm{min})$. The GPC system was calibrated against Pullulan standards (180-708 $000 \mathrm{Da})$. The samples $(2 \mathrm{mg} / \mathrm{mL})$ were dissolved in the eluent and filtered through syringe filters $(0.2 \mu \mathrm{m})$. Data analyses were performed in Origin Pro 2018 .

Differential Scanning Calorimetry (DSC). DSC (Mettler Toledo DSC2 calorimeter equipped with an HSS7 sensor and a TC-125MT intercooler) was conducted under a dry nitrogen atmosphere. Samples $(5 \mathrm{mg})$ were placed in sealed aluminum pans for all DSC runs. A heating/cooling/heating procedure was applied over a temperature range from 30 to $250{ }^{\circ} \mathrm{C}$ and -100 to $230^{\circ} \mathrm{C}$ for neat $\mathrm{AX}$ and dA-AX and GE-dA-AX samples, respectively, at $10^{\circ} \mathrm{C} / \mathrm{min}$. Two specimens from each material were analyzed. $T_{\mathrm{g}}$ was taken as the inflection point of the endotherm transition(s) in the second heating cycle. Representative heating-cooling-heating cycles juxtaposed with highlighted endotherm(s) in the second heating cycle for all samples are shown in Figures S8-S13.

Thermogravimetric Analysis (TGA). The thermal stability was evaluated on a TGA/DSC 3+ Star System (Mettler Toledo, Columbus, $\mathrm{OH}$ ) at a heating rate of $5{ }^{\circ} \mathrm{C} / \mathrm{min}$ between 25 and 500 ${ }^{\circ} \mathrm{C}$ under a $\mathrm{N}_{2}$ flow of $50 \mathrm{~mL} / \mathrm{min}$. In total, $5 \mathrm{mg}$ for each sample in duplicate was analyzed.

Uniaxial Tensile Test. Tensile tests were performed at room temperature on a universal testing machine Instron 5565A (Norwood, MA) equipped with a load cell of $100 \mathrm{~N}$ at $30 \mathrm{~mm} / \mathrm{min}$ crosshead speed. Rectangular specimens with gauge dimensions of $20 \mathrm{~mm}$ length, $5.6 \mathrm{~mm}$ width, and $0.4 \mathrm{~mm}$ (0.11 for solvent-cast films) thickness cut from films obtained from compressed molding were tested. They were air-dried and conditioned at $23{ }^{\circ} \mathrm{C}$ and $50 \% \mathrm{RH}$ for $24 \mathrm{~h}$ before measurements (4-5 replicates).

\section{RESULTS AND DISCUSSION}

Figure 2 depicts the synthesis strategy of the AX thermoplastics. To investigate the structural composition-propertyprocessing correlation, different activated AX ethers were synthesized, which varied in structure and composition. First, thermal processability is determined followed by structural and molar mass characterizations and thermomechanical property determination. The relationship between the molar substitutions of different glycidyl ethers in activated arabinoxylan 

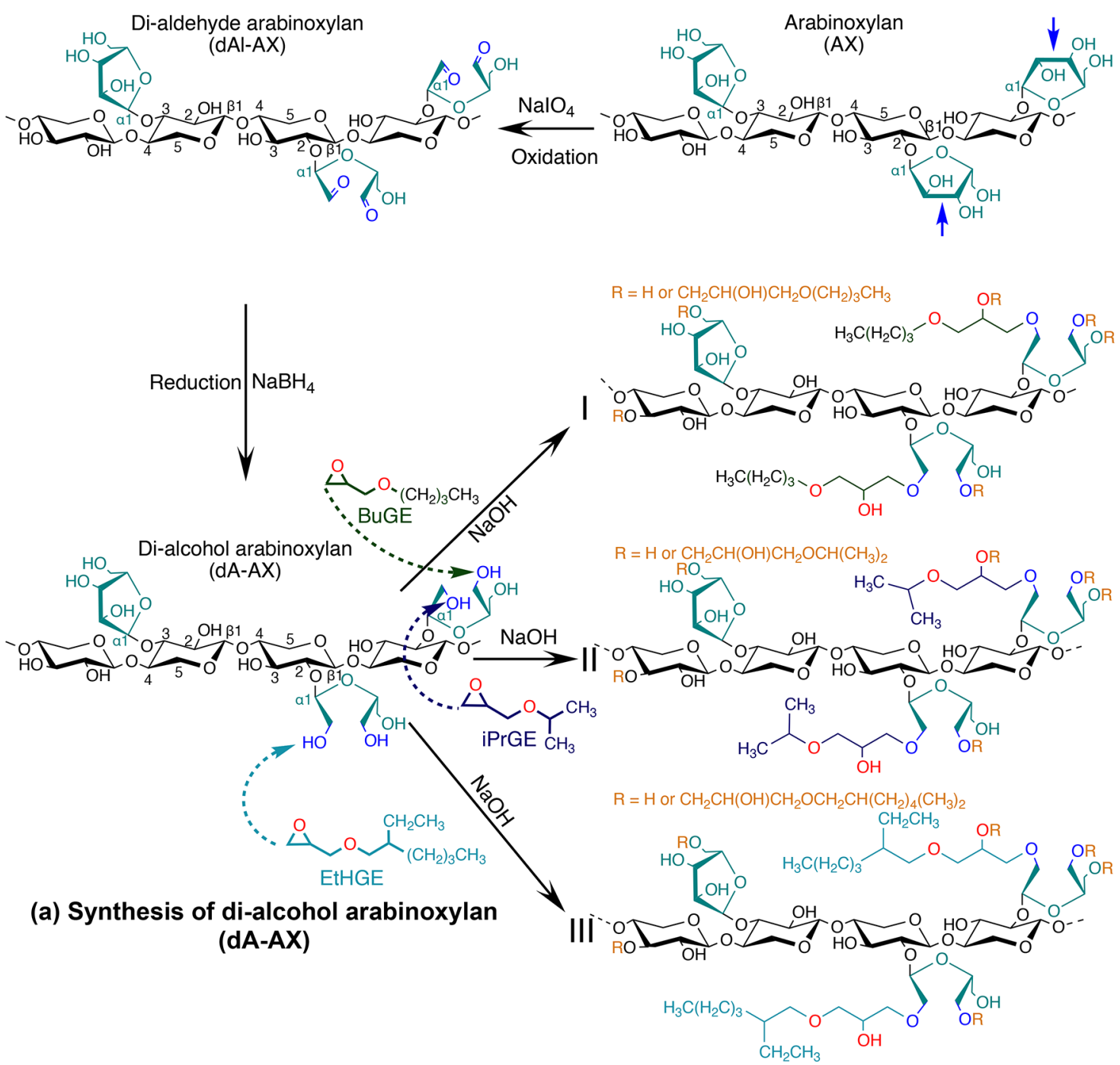

(b) Synthesis of glycidyl etherified di-alcohol arabinoxylan (GE-dA-AX)

Figure 2. Two-step-synthesis route of glycidyl-etherified di-alcohol arabinoxylans. (a) Step 1-synthesis of di-alcohol arabinoxylan (dA-AX) by successive periodate oxidation and reduction of arabinoxylan (AX). (b) Step 2-synthesis of glycidyl-etherified di-alcohol arabinoxylan from dAAX using three etherification agents (BuGE, iPrGE, EtHGE). Three different types (I, II, III) are synthesized.

ethers and their thermal processing and thermomechanical properties is discussed in the end.

Chemical and Structure Characterization. The neat $\mathrm{AX}, \mathrm{dA}-\mathrm{AX}$, and activated AX ethers are structurally and chemically analyzed.

FTIR. To verify the coupling of GEs on the activated AX, ATR-FTIR was employed to compare the changes in functional groups. Figure 3 shows the spectrum of neat $\mathrm{AX}$ and the spectra of representative samples from $\mathrm{dA}-\mathrm{AX}$ and GE-dA-AXs. The spectra of all of the samples are shown in Figure S3. The $\mathrm{OH}$ stretching band centered at $\sim 3300 \mathrm{~cm}^{-1}$ shifted left for BuGE-dA-AX samples, implying that introducing etherification agents weakens hydrogen bonding. There are no significant changes in the $\mathrm{OH}$ absorbance because of the consumption and generation of $\mathrm{OH}$ groups upon epoxidation. The same band remained unaltered or shifted left for $i$ PrGE-dA-AX and EtHGE-dA-AX samples. The new bands observed between 3000 and $2850 \mathrm{~cm}^{-1}$ and between 1500 and $1350 \mathrm{~cm}^{-1}$ are related to alkyl ${ }^{47,48}\left(\mathrm{CH}_{2}\right.$ and $\mathrm{CH}_{3}$ ) groups' stretching and bending of the BuGE (strong) and $i \operatorname{PrGE}$ (mild) structures in GE-dA-AX samples. A new band at $\sim 740 \mathrm{~cm}^{-1}\left(\mathrm{CH}_{2}\right.$ rocking vibration) plus its counterpart at $\sim 1465 \mathrm{~cm}^{-1}$ (stronger $\mathrm{CH}_{2}$ vibration) is specific to BuGE-dA-AX samples and shows a long-chain linear aliphatic structure. ${ }^{48}$ These bands were not apparent in the EtHGE-dA-AX sample, showing unsuccessful etherification reactions. The bands between 1600 and $1500 \mathrm{~cm}^{-1}$ (not highlighted) are of residual water in the samples. ${ }^{49}$ The different amounts of water may be present in the samples as evidenced by the product yields (Table S3), which change with modification.

Intact Carbohydrate Substitution (ICS). ICS determines the substitution of the etherification agents on $\mathrm{OH}$ groups of intact carbohydrates in a dA-AX polymer (for calculation, see eq 3 and Figure S1 in the Supporting Information), and Table 2 presents the ICS values. Up to $58 \%$ (ICS-0.58) sugar units were BuGE-etherified on $\mathrm{dA}_{19 \%}$-AX sample (entry 2 in Table 2) contrary to $37 \%$ (entry 3 in Table 2 ) on $\mathrm{dA}_{31 \%}$-AX for $3 \mathrm{~mol}$ equiv of BuGE. This suggests that increasing oxidation level from 19 to $31 \%$ creates a higher quantity of ring-opened sugar 
Table 1. Sample Codes, Synthesis Parameters, and Characterizations of Activated Arabinoxylans (dA-AX) and Activated Arabinoxylan Ethers (GE-dA-AX)

\begin{tabular}{|c|c|c|c|c|}
\hline \multirow[b]{2}{*}{ sample ID ${ }^{a}$} & \multicolumn{3}{|c|}{$\begin{array}{c}\text { activated arabinoxylan ( } \mathrm{dA}-\mathrm{AX}) \\
\text { [periodate-oxidized and reduced } \mathrm{AX}]\end{array}$} & \multirow{2}{*}{$\begin{array}{c}\text { activated } \\
\text { arabinoxylan } \\
\text { ether (GE-dA- } \\
\mathrm{AX}) \\
\text { mol equiv of } \\
\mathrm{NaOH} / \mathrm{ASU} \text { and } \\
\mathrm{GE} / \mathrm{ASU}^{e}\end{array}$} \\
\hline & $\begin{array}{c}\text { mol of } \\
\text { PI/ } \\
\mathrm{ASU}^{b}\end{array}$ & $\begin{array}{c}\text { oxidation } \\
\text { level } 1^{c} \\
\left(\mathrm{OL}_{\mathrm{UV}-\mathrm{vis}}\right) \\
(\%)\end{array}$ & $\begin{array}{c}\text { oxidation } \\
\text { level } 2^{d} \\
\left(\mathrm{OL}_{\mathrm{SCB}}\right) \\
(\%)\end{array}$ & \\
\hline $\mathrm{GE}_{1.0} \mathrm{dA}_{19 \%} \mathrm{AX}$ & 0.25 & 19 & 23 & 1 \\
\hline $\mathrm{GE}_{3.0} \mathrm{dA}_{19 \%} \mathrm{AX}$ & 0.25 & 19 & 23 & 3 \\
\hline $\mathrm{GE}_{3.0} \mathrm{dA}_{31 \%} \mathrm{AX}$ & 0.35 & 31 & 27 & 3 \\
\hline $\mathrm{GE}_{5.0} \mathrm{dA}_{31 \%} \mathrm{AX}$ & 0.35 & 31 & 27 & 5 \\
\hline
\end{tabular}

${ }^{a}$ First superscripted number from left-mole of glycidyl ethers (GEs), second superscripted number in \%-ultraviolet-visible (UV-vis) measured oxidation level; this sample code is generic; specific glycidyl ether is prefixed in the code (e.g., $\left.\mathrm{BuGE}_{1.0} \mathrm{dA}_{19 \%} \mathrm{AX}\right) .{ }^{b}$ Mole equivalence of periodate (PI)/anhydrous sugar unit (ASU; sugarpentose plus minor hexose), reduction reaction's parameters were similar for all reactions. ${ }^{c} \mathrm{UV}-\mathrm{vis}$ determined oxidation level. ${ }^{d}$ Oxidation level based on sugar content reduction after oxidation and reduction. ${ }^{e}$ Mole equivalence of $\mathrm{NaOH}$ and glycidyl ether (GE)/ anhydrous sugar unit (ASU) were similar.

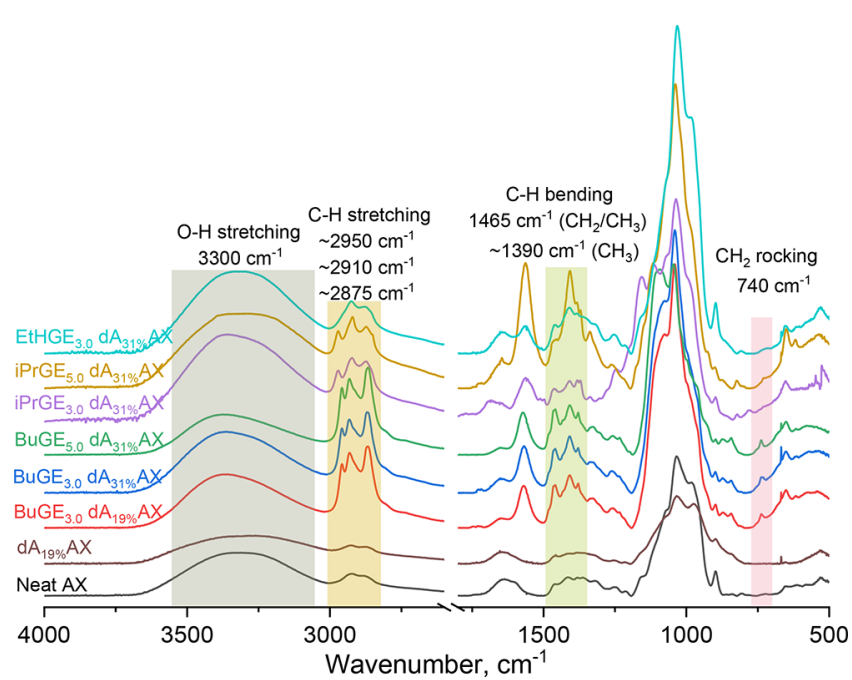

Figure 3. IR spectrum of neat $A X$ and representative spectra of dialcohol AX and three different glycidyl-etherified di-alcohol AXs.

units (i.e., alkyl and alkoxy chains) and these chains may block access to intact sugar units in the polymer. Increasing BuGE from $3 \mathrm{~mol}$ equiv to 5 eased this blockage, as ICS was 0.76 for the $B_{0 u G} \mathrm{dA}_{31 \%} \mathrm{AX}$ sample (entry 4 in Table 2). The substitution was lower for $i$ PrGE-dA-AX samples (maximum $=0.46$ for $i \operatorname{PrGE}_{5.0} \mathrm{dA}_{31 \%} \mathrm{AX}$ ) in comparison with BuGE-dAAX samples, most likely owing to its terminal isopropyl branch. ICS values were zero/negative (very close to zero) for EtHGE-dA-AX samples, showing that EtHGE did not react. This has to do with the longer and branched carbon chain in EtHGE (Figure 2) and its lowest water solubility (0.02\%, Table S1) among three glycidyl ethers. This longer and branched carbon chain in EtHGE compared to BuGE and $i$ PrGE may have prevented EtHGE monomers to react with the $\mathrm{OH}$ groups of the activated AX. Negative ICS values maybe because of the insignificant degradation of sugars during the alkaline treatment step in the synthesis of activated AX ethers (GE-dA-AX) (refer Experimental Section) because ICS values are based on the reduction of sugar content (determined by HPLC using eq 3 in the Supporting Information) after glycidyl ether substitution. These results agree with the FTIR results.

${ }^{1} H$ NMR. We employed ${ }^{1} \mathrm{H}$ NMR to evaluate the molar substitution (MS) of different etherification agents (BuGE, $i$ PrGE, EtHGE) in the GE-dA-AX samples (Table 2). Increasing BuGE amount from 1 to $3 \mathrm{~mol}$ and 3 to $5 \mathrm{~mol}$ (keeping oxidation level same 19 and $31 \%$ ) produces a sharp increase ( 0.38 to 3.39 ; entries 1 to 3 in Table 2) and moderate increase (3.39 to 4.41 ; entries 3 and 4 in Table 2) in MS showing the excess need of BuGE to react on $\mathrm{OH}$ groups. The MS does not alter (3.10 and 3.39) when increasing the oxidation level from 19 to $31 \%$ at the same BuGE amount (3 mol equiv), showing (1) the requirement of minimum oxidation level; (2) increasing oxidation above that level does not yield any further advantage. The BuGE sample with $31 \%$ oxidation level and $5 \mathrm{~mol}$ equiv produced a gluey and heterogeneous film when compression-molded. This signifying toward avoiding the use of over 5 mol equiv BuGE in combination with the least oxidation level because BuGE most likely remained unattached after saturation.

The MS values of BuGE-dA-GE samples were higher than iPrGE-dA-AX samples. We observed the MS increases with an increase in both oxidation level and mole equivalence of BuGE and $i$ PrGE. However, the MS values of the EtHGE-dA-AX samples were close to zero, signifying that EtHGE did not react with dA-AX samples despite increasing the oxidation level and glycidyl ether amount (NMR spectrum in Figure S7).

This has to do with the branched alkoxide chain in EHGE, which may create steric hindrance to reach on the $\mathrm{OH}$ groupreacting sites on di-alcohol $\mathrm{AX}$ samples compared to BuGE having a linear carbon chain (Figure 2). This steric hindrance and low water solubility of EtHGE may have rendered almost nil MS for EtHGE-dA-AX samples and make these samples thermally incompressible. To find whether $\mathrm{OH}$ groups of the epoxide ring-opened glycidyl ether moieties may serve as initiation sites for the polymerization of glycidyl ethers to make polyether on the di-alcohol $\mathrm{AX}, 3$ and $5 \mathrm{~mol}$ equiv of BuGE, $i$ PrGE, and EtHGE were reacted under the same etherification reaction conditions but without dA-AX. ${ }^{1} \mathrm{H}$ NMR (Figures S4-S6) spectra did not provide any support to this possibility because the glycidyl ethers were converted to their corresponding di-ols. Polyethers were formed from different glycidyl ethers using $t$-Bu-P4 (superbase) and $n$-butanol. ${ }^{50}$ However, a separate in-depth investigation is needed to prove this.

Molar Mass Distribution. Table 2 presents average molar masses and polydispersity indices of neat AX and GE-dA-AX samples. $M_{\mathrm{n}}$ and $M_{\mathrm{w}}$ of neat $\mathrm{AX}$ are close to those of wheat $\mathrm{AX}$ (low viscosity) from an earlier study using DMSO as a solvent ${ }^{51}$ but lower than those of another study. ${ }^{36}$ DMSObased size exclusion chromatography (SEC) (used in this study) offers lower average molar masses compared to waterbased SEC. ${ }^{51}$ The molar masses could not be obtained for the di-alcohol samples because they were not soluble in DMSO. The molecular weights were decreased after oxidation because of the degradation of the AX polymers. ${ }^{36}$ Number-average molar masses and polydispersity indices of the GE-dA-AX samples increase and decrease in comparison with neat AX. $M_{w}$ did not follow any trend. The molar masses' moments of neat AX and GE-dA-AX samples are in Figure S2. 
Table 2. Molar Substitutions (MS), Intact Carbohydrate Substitutions (ICS), and Molar Mass Averages $\left(M_{n}, M_{w}\right)$ and Polydispersity Indices ( () of Neat AX and Glycidyl-Etherified Di-Alcohol AXs (GE-dA-AXs)

\begin{tabular}{|c|c|c|c|c|c|c|}
\hline \multirow[b]{2}{*}{ entry } & \multirow[b]{2}{*}{ sample } & \multirow[b]{2}{*}{$\mathrm{MS}^{a}$} & \multirow[b]{2}{*}{$\mathrm{ICS}^{b}$} & \multicolumn{3}{|c|}{ molecular weight moments and polydispersity indices } \\
\hline & & & & $M_{\mathrm{n}}(\mathrm{kDa})$ & $M_{\mathrm{w}}(\mathrm{kDa})$ & $\left(M_{\mathrm{w}} / M_{\mathrm{n}}\right), \Xi^{c}$ \\
\hline 0 & neat $\mathrm{AX}$ & na & na & $31(0.4)$ & $163(3.1)$ & 5.4 \\
\hline 1 & $\mathrm{BuGE}_{1.0} \mathrm{dA}_{19 \%} \mathrm{AX}$ & 0.38 & 0.10 & $35(0.8)$ & $156(0.1)$ & 4.5 \\
\hline 2 & $\mathrm{BuGE}_{3.0} \mathrm{dA}_{19 \%} \mathrm{AX}$ & 3.10 & 0.58 & $55(0.4)$ & $177(0.8)$ & 3.2 \\
\hline 3 & $\mathrm{BuGE}_{3.0} \mathrm{dA}_{31 \%} \mathrm{AX}$ & 3.39 & 0.37 & $32(0.0)$ & $133(1.2)$ & 4.1 \\
\hline 4 & $\mathrm{BuGE}_{5.0} \mathrm{dA}_{31 \%} \mathrm{AX}$ & 4.41 & 0.76 & $45(*)$ & $149(*)$ & 3.3 \\
\hline 5 & $i \operatorname{PrGE}_{1.0} \mathrm{dA}_{19 \%} \mathrm{AX}$ & 0.02 & 0.00 & $34(0.1)$ & $133(1.0)$ & 3.9 \\
\hline 6 & $i \operatorname{PrGE}_{3.0} \mathrm{dA}_{19 \%} \mathrm{AX}$ & 0.24 & 0.31 & $37(0.2)$ & $151(1.8)$ & 4.1 \\
\hline 7 & $i \operatorname{PrGE}_{3.0} \mathrm{dA}_{31 \%} \mathrm{AX}$ & 0.16 & 0.10 & $34(0.4)$ & $76(0.5)$ & 2.3 \\
\hline 8 & $i \operatorname{PrGE}_{5.0} \mathrm{dA}_{31 \%} \mathrm{AX}$ & 0.60 & 0.46 & $49(3.9)$ & $156(0.4)$ & 3.2 \\
\hline 9 & $\mathrm{EtHGE}_{1.0} \mathrm{dA}_{19 \%} \mathrm{AX}$ & nd & - & $44(1.3)$ & $168(1.1)$ & 3.8 \\
\hline 10 & $\mathrm{EtHGE}_{3.0} \mathrm{dA}_{19 \%} \mathrm{AX}$ & 0.08 & - & $43(0.5)$ & $132(0.0)$ & 3.1 \\
\hline 11 & $\mathrm{EtHGE}_{3.0} \mathrm{dA}_{31 \%} \mathrm{AX}$ & 0.06 & - & $40(0.6)$ & $178(0.3)$ & 4.5 \\
\hline 12 & $\mathrm{EtHGE}_{50} \mathrm{dA}_{310 \%} \mathrm{AX}$ & 0.02 & - & $46(0.4)$ & $122(0.3)$ & 3.4 \\
\hline
\end{tabular}

${ }^{a}$ Molar substitution (MS) of glycidyl ethers determined by ${ }^{1} \mathrm{H}$ NMR. ${ }^{b}$ Intact carbohydrate substitution (ICS) determined by HPLC. ${ }^{c}$ Polydispersity index $Ð\left(M_{\mathrm{w}} / M_{\mathrm{n}}\right)$. nd, could not be determined. na, not applicable. Values were negative close to zero; data in parentheses are the standard deviation of two replicates. * Data not available (one replicate).
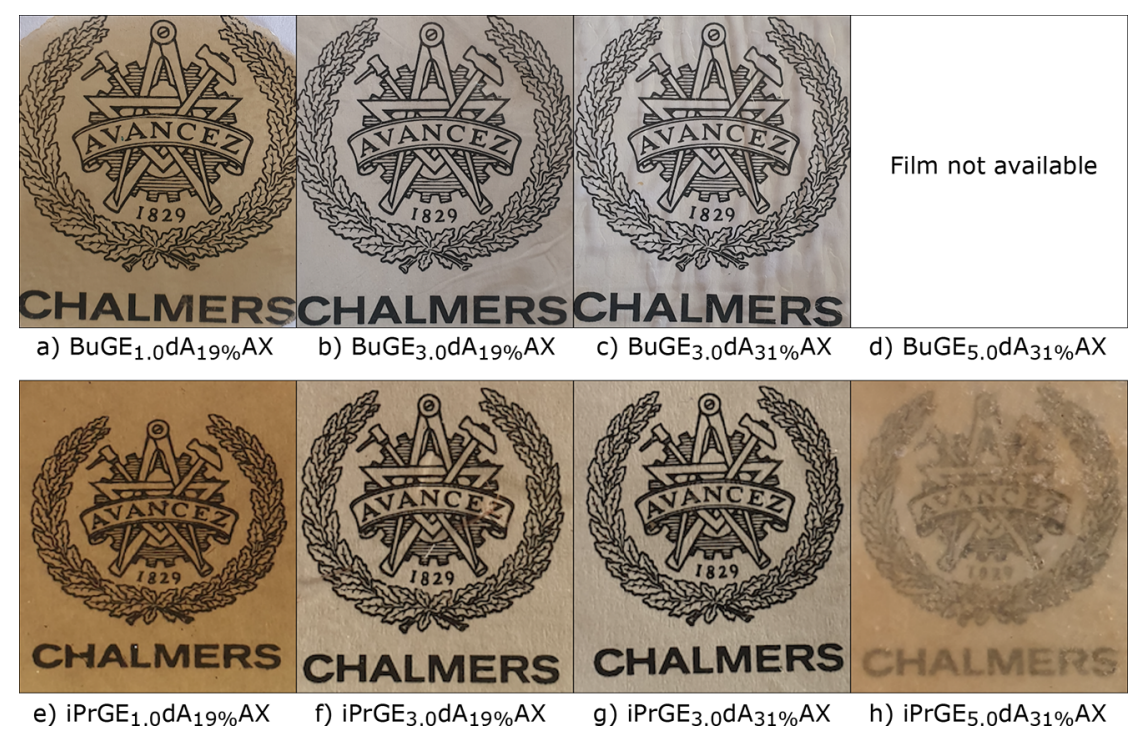

Figure 4. Films fabricated from the activated $\mathrm{AX}$ ethers using BuGE $(\mathrm{a}-\mathrm{d})$ and $i \operatorname{PrGE}(\mathrm{e}-\mathrm{h})$ via compression molding at $140{ }^{\circ} \mathrm{C}$ and $50 \mathrm{kPa}$ pressure. The Chalmers logo is used to determine the transparency of the films. Chalmers University of Technology gave permission to use and does not claim any copyrights. $\mathrm{BuGE}_{5.0} \mathrm{dA}_{31 \%} \mathrm{AX}$ film (d) is not available because the material was too soft to form a free-standing film.

Thermal Processing. Compression molding, injection molding, and extrusion are the most common thermal processing techniques used for synthetic polymers. In the present work, compression molding $\left(140{ }^{\circ} \mathrm{C}\right.$ and $\left.50 \mathrm{kPa}\right)$ was used to find out whether the activated $\mathrm{AX}$ ethers were thermally processable. All activated AX ethers synthesized using BuGE and $i$ PrGE were compression-moldable, and Figure 4 shows the representative images of the films. These results suggest the possibility of achieving thermal processability in arabinoxylan both using other reactants (i.e., iPrGE) and using different combinations of the activation level and quantity of BuGE and iPrGE. The activated AX ethers synthesized using EtHGE could not be compression-molded. We might attribute this to the lowest water solubility $(0.02 \%$, Table S1) of EtHGE among three glycidyl ethers as compared to other etherification agents (Table S1). To increase the solubility of EtHGE in the etherification reaction, ethanol and water (30 and $70 \%)$ mix was used, but the product was still not compression-moldable. The $\mathrm{BuGE}_{5.0} \mathrm{dA}_{31 \%} \mathrm{AX}$ material yielded a gluey and heterogeneous film. The films were transparent except for the one fabricated from the $i \operatorname{PrGE}_{5.0} \mathrm{dA}_{31 \%} \mathrm{AX}$ material. The yellowness of the films shows the degradation of low-molecular-weight carbohydrates and proteins or nonstructural compounds during compression molding. ${ }^{52,53}$

\section{THERMAL AND MECHANICAL PROPERTIES}

Thermal Properties. Glass-Transition Temperature. $T_{\mathrm{g}}$ values of neat $A X, d A-A X$, and GE-dA-AX samples were determined from DSC and are shown in Table 3. The DSC thermograms are available in Figures S8-S13. We observed no significant changes in $T_{\mathrm{g}}$ of $\mathrm{dA}-\mathrm{AX}$ samples oxidized at 19 and $31 \%$ levels (193 and $188^{\circ} \mathrm{C}$ ) compared to that of the neat AX $\left(189^{\circ} \mathrm{C}\right)$, showing that $T_{\mathrm{g}}$ is independent of oxidation level in AX. It is worth noting that the molar ratio of arabinofuranosyl to xylopyranosyl (Araf/Xylp) units remains unchanged ( 0.7) at two oxidation levels (Table S4). Likewise, the $T_{\mathrm{g}}$ of $\mathrm{AX}$ 
Table 3. DSC, Tensile (Tensile Test), and Thermogravimetric (TGA) Data of Neat AX, dA-AXs, and GE-dA-AXs

\begin{tabular}{|c|c|c|c|c|c|c|c|c|c|}
\hline \multirow[b]{2}{*}{ sample } & \multicolumn{2}{|c|}{ DSC data ${ }^{a}$} & \multicolumn{3}{|c|}{ tensile data $^{b}$} & \multicolumn{4}{|c|}{ thermogravimetric data ${ }^{c}$} \\
\hline & $T_{\mathrm{g}} 1\left({ }^{\circ} \mathrm{C}\right)$ & $T_{\mathrm{g}} 2\left({ }^{\circ} \mathrm{C}\right)$ & $E(\mathrm{MPa})$ & $\sigma_{\mathrm{t}}(\mathrm{MPa})$ & $\varepsilon_{\mathrm{b}}(\%)$ & $\begin{array}{l}T_{\text {onset }} \\
\left({ }^{\circ} \mathrm{C}\right)\end{array}$ & $T_{\text {inflection }}$ & $\begin{array}{c}T_{\text {endset }} \\
\left({ }^{\circ} \mathrm{C}\right)\end{array}$ & $\begin{array}{l}\text { final residue (FR) } \\
(\%)\end{array}$ \\
\hline neat $\mathrm{AX}^{\ddagger}$ & $189(3)$ & na & $1632(47)$ & $31(10)$ & $4(1)$ & $261(1)$ & $282(3)$ & $298(0)$ & $25.9(1)$ \\
\hline $\mathrm{dA}_{19 \%} \mathrm{AX}$ & $193(0)$ & na & - & - & - & $269(3)$ & $285(1)$ & $301(3)$ & $41.0(2)$ \\
\hline $\mathrm{dA}_{31 \%} \mathrm{AX}$ & $188(1)$ & na & - & - & - & $269(1)$ & $287(2)$ & $311(1)$ & $42.5(0)$ \\
\hline $\mathrm{BuGE}_{1.0} \mathrm{dA}_{19 \%} \mathrm{AX}^{\ddagger}$ & $123(1)$ & na & $1517(228)$ & $52(8)$ & $19(2)$ & $265(2)$ & $298(2)$ & $320(1)$ & $23.8(1)$ \\
\hline $\mathrm{BuGE}_{3.0} \mathrm{dA}_{19 \%} \mathrm{AX}$ & $-54(0)$ & $163(2)$ & $2(0)$ & $1(0)$ & $244(42)$ & $238(2)$ & $295(2)$ & $320(1)$ & $18.1(0)$ \\
\hline $\mathrm{BuGE}_{3.0} \mathrm{dA}_{31 \%} \mathrm{AX}$ & $-57(1)$ & $156(2)$ & $0.4(0)$ & $0.2(0)$ & $267(72)$ & $212(2)$ & $300(1)$ & $327(2)$ & $15.7(0)$ \\
\hline $\mathrm{BuGE}_{5.0} \mathrm{dA}_{31 \%} \mathrm{AX}$ & $-67(1)$ & $176(10)$ & nd & nd & nd & $202(9)$ & $237(11)$ & $324(0)$ & $10.5(0)$ \\
\hline$i \operatorname{PrGE}_{1.0} \mathrm{dA}_{19 \%} \mathrm{AX}^{\ddagger}$ & $100(0)$ & na & $1024(113)$ & $23(6)$ & $4(1)$ & $264(0)$ & $294(2)$ & $316(0)$ & $31.4(0)$ \\
\hline$i \operatorname{PrGE}_{3.0} \mathrm{dA}_{19 \%} \mathrm{AX}$ & $69(3)$ & na & $42(18)$ & $4(0)$ & 45 (19) & $248(2)$ & $285(6)$ & $316(0)$ & $27.3(0)$ \\
\hline${ }_{i} \operatorname{PrGE}_{3.0} \mathrm{dA}_{31 \%} \mathrm{AX}$ & $70(1)$ & na & $240(157)$ & $10(6)$ & $23(9)$ & $251(5)$ & $285(6)$ & $316(5)$ & $28.1(4)$ \\
\hline$i \operatorname{PrGE}_{5.0} \mathrm{dA}_{31 \%} \mathrm{AX}$ & $54(6)$ & na & $32(25)$ & $2(1)$ & $60(19)$ & $259(1)$ & $290(1)$ & $315(1)$ & $24.8(1)$ \\
\hline $\mathrm{EtHGE}_{3.0} \mathrm{dA}_{19 \%} \mathrm{AX}$ & $143(11)$ & na & - & - & - & $242(*)$ & $279(*)$ & $314(*)$ & $26.5(*)$ \\
\hline
\end{tabular}

${ }^{a} T_{\mathrm{g}}$ was obtained from DSC second heating scan and data in parentheses are the standard deviations of two replicates. ${ }^{b}$ Data in parentheses are standard deviations of $4-5$ replicates. ${ }^{c}$ Data in parentheses are standard deviations of two replicates; $E$, Young's modulus; $\sigma_{\mathrm{t}}$, max tensile stress; $\varepsilon_{\mathrm{b}}$,

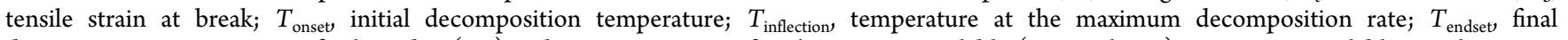
decomposition temperature; final residue (FR) — char content at $500{ }^{\circ} \mathrm{C}$. * Data not available (one replicate). - Data not available as solvent-cast films were too fragile/brittle. nd, Not determined because the film was too soft to be handled at room temperature. $¥$ Solvent-cast films were used for tensile tests. na, Second endotherm was not observed in the DSC scans.

(Araf/Xylp 1.1) was shown to remain unchanged upon oxidation in an earlier study. ${ }^{36}$ Considering our results and previous study results, we hypothesize that $T_{\mathrm{g}}$ does not alter when Araf/Xylp is $>0.7$ because arabinosyl units create steric hindrance, limiting the oxidation of the xylan chains, keeping the xylan backbone stiff, and restricting the rotational freedom of the xylan for being bulky pyranose rings. In contrast, we found $T_{\mathrm{g}}$ of xylan to decrease upon oxidation for xylan ${ }^{36}$ because of the pyranose ring opening in the xylan backbone.

It becomes clear that $T_{\mathrm{g}}$ of the activated $\mathrm{AX}$ ethers $\left(T_{\mathrm{g}}\right.$ ranged between -67 and $143{ }^{\circ} \mathrm{C}$ ) reduced compared to their counterparts, i.e., neat $\mathrm{AX}$ and dA-AX samples $\left(T_{\mathrm{g}} \sim 189^{\circ} \mathrm{C}\right)$ (Table 3 ). The reduction in $T_{\mathrm{g}}$ was expected because of the coupling of etherification agents on activated AX due to the disruption of intermolecular interactions. When comparing $T_{\mathrm{g}}$ among GE-dA-AX samples of different etherification agents, the reduction in $T_{\mathrm{g}}$ is the most pronounced for BuGE-dA-AXs $\left(123,-50,-57,-67^{\circ} \mathrm{C}\right)$, moderately pronounced for $i$ PrGEdA-AXs $\left(100,69,70,54{ }^{\circ} \mathrm{C}\right)$, and least pronounced for EtHGE $_{3.0} \mathrm{dA}_{19 \%} \mathrm{AX}\left(143{ }^{\circ} \mathrm{C}\right)$. We also observed a second endotherm for $\mathrm{BuGE}_{3.0} \mathrm{dA}_{19 \%} \mathrm{AX}\left(163{ }^{\circ} \mathrm{C}\right), \mathrm{BuGE}_{3.0} \mathrm{dA}_{31 \%} \mathrm{AX}$ $\left(156{ }^{\circ} \mathrm{C}\right)$, and $\mathrm{BuGE}_{5.0} \mathrm{dA}_{31 \%} \mathrm{AX}\left(176{ }^{\circ} \mathrm{C}\right)$ (Figure S9 in the $\mathrm{SI})$. This peculiar nature of two endotherms originates from the structure and composition of these samples and hydrophobic nature and lower water solubility [2\%, compared to $i$ PrGE (18\%), see Table S1] of BuGE. This situation may arise from microphase separation because of the coexistence of densely and lightly changed regions within the polymer. The densely and lightly changed regions may relate to the nonpolar domain formed by a hydrophobic alkoxide butyl chain and polar domain from low-degree-modified or unmodified polysaccharides. The absence of two glass transitions for iPrGE-dA-AXs (Table 3) may be linked to the hydrophilic nature of $i \operatorname{PrGE}$ [highest water solubility (18\%) among tested glycidyl ethers, see Table S1]. This hydrophilic $i$ PrGE could have facilitated the compatibilization of two phases/domains. The subzero endotherm $\left(-50,-56,-67{ }^{\circ} \mathrm{C}\right)$ may be assigned to longer alkoxide side chains (sugar ring-opened sugar alkyl plus epoxide ring-opened BuGE alkyl chain), and the second endotherm $\left(163,156,176{ }^{\circ} \mathrm{C}\right)$ is because of the xylan backbone (Figure S9).

Remember that a new band at $\sim 740 \mathrm{~cm}^{-1}\left(\mathrm{CH}_{2}\right.$ rocking vibration) plus its counterpart at $\sim 1465 \mathrm{~cm}^{-1}$ (stronger $\mathrm{CH}_{2}$ vibration) specific to BuGE-dA-AX samples was observed and showed a long-chain linear aliphatic structure ${ }^{48}$ (Figures 3 and S3b). Coupling of $n$-butyl glycidyl ether and propylene oxide (without oxidation and reduction) on hardwood hemicellulose lowered $T_{\mathrm{g}}$ to 124 and $175{ }^{\circ} \mathrm{C}^{35}$ because the polymer lacked ring-opened sugar alkyl chains. This suggests that the subzero endotherm transition may arise from the longer alkyl or alkoxide side chains. Contrary to two endotherms in the BuGE-dA-AX samples, $i$ PrGE-dA-AX samples possess only one endotherm above zero, i.e., $T_{g} 100,69,70$, and $54{ }^{\circ} \mathrm{C}$ (Table 3 and Figures S10-S1 $1 a^{\prime}, b^{\prime}$ ). This is also in agreement with a study on evaluating relations between thermal transition, structure, and morphology of the conjugated polymers, ${ }^{54}$ reinforcing that longer alkyl/alkoxide side chains create a dominating subzero endotherm apart from the backbone endotherm. Two glass transitions are common for multiblock synthetic polymers, ${ }^{55,56}$ conjugated polymers, ${ }^{54}$ esterified cellulose, ${ }^{57}$ lignin-based thermoplastics, ${ }^{58,59}$ thermoplastic elastomers (TPEs). ${ }^{60}$ This justifies the use of multiple techniques such as broadband dielectric spectroscopy, variable temperature ellipsometry, and DMA to probe the different transitions arising from the backbone and long side chains.

Thermal Stability. Thermal stabilities of neat AX, dA-AX, and GE-dA-AX samples were investigated using TGA, and the results are presented in Table 3. The TG thermograms (Figure $\mathrm{S} 14 \mathrm{a})$ reveal that all samples possess one-step decomposition profiles. The major decomposition $\left(T_{\text {inflection }}\right)$ of the BuGE $_{5.0} \mathrm{dA}_{31 \%} \mathrm{AX}$ sample takes place at $\sim 237{ }^{\circ} \mathrm{C}$ with a shoulder at $\sim 200{ }^{\circ} \mathrm{C}$ (Table 3 and Figure S14c) contrary to the other samples that decompose between 280 and $300{ }^{\circ} \mathrm{C}$ (Table 3 and Figure S14c,d). This has to do with the gluey nature of this film upon compression molding. The di-alcohol AXs (dA-AXs) $\left(\mathrm{dA}_{19 \%} \mathrm{AX}\right.$ and $\left.\mathrm{dA}_{31 \%} \mathrm{AX}\right)$ exhibit higher thermal stability compared to neat $\mathrm{AX}$, as the onset decomposition 

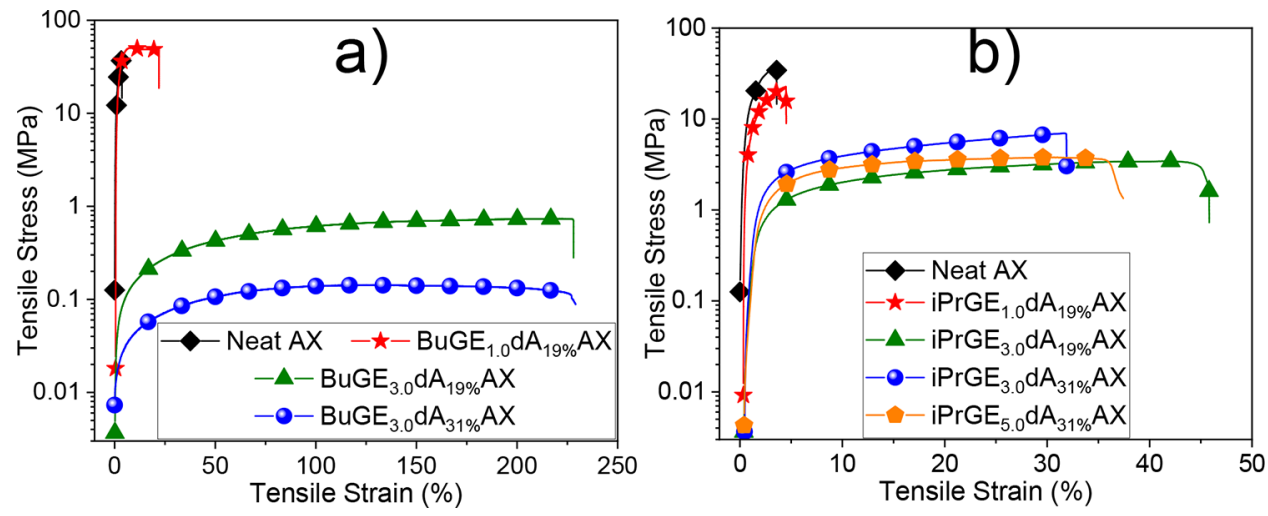

Figure 5. Representative stress-strain curves of (a) BuGE- and (b) iPrGE-etherified di-alcohol AX samples.
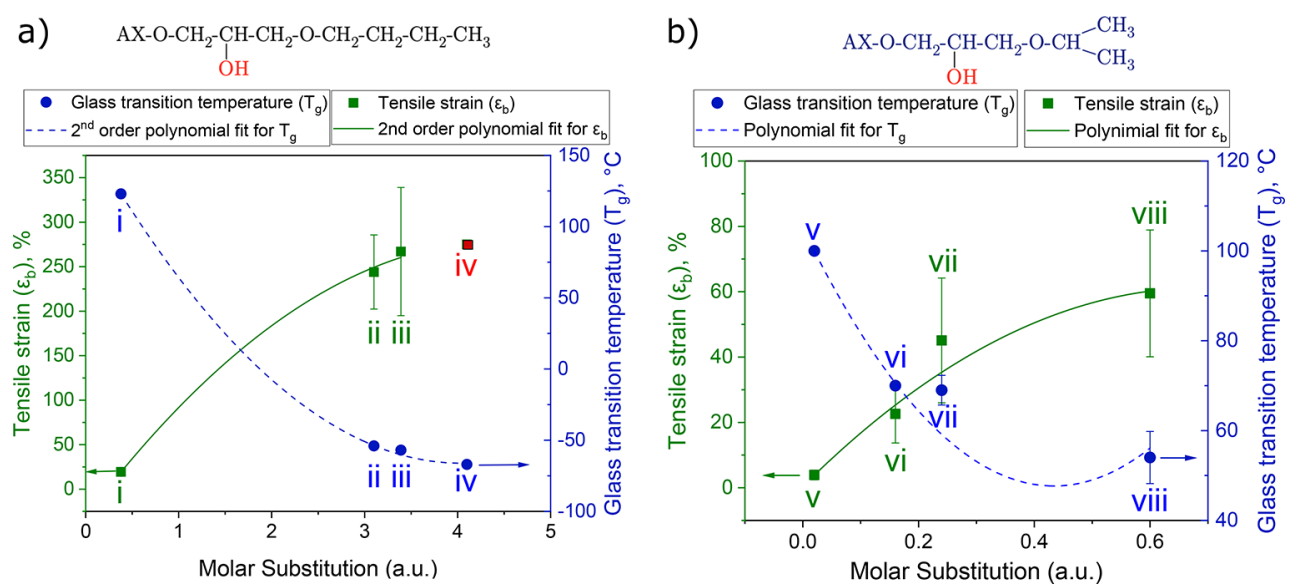

Figure 6. Molar substitution-property (tensile strain and $T_{\mathrm{g}}$ ) correlation. (a) Evolution of tensile strain and $T_{\mathrm{g}}$ against the molar substitution of BuGE-etherified dA-AX samples. (i) -(iv) BuGE $\mathrm{Bu}_{1.0} \mathrm{dA}_{19 \%} \mathrm{AX}, \mathrm{BuGE}_{3.0} \mathrm{dA}_{19 \%} \mathrm{AX}, \mathrm{BuGE}_{3.0} \mathrm{dA}_{31 \%} \mathrm{AX}$, and $\mathrm{BuGE}_{5.0} \mathrm{~d} \mathrm{~A}_{31 \%} \mathrm{AX}$. The red square represents the logical expected tensile strain of the $\mathrm{BuGE}_{5.0} \mathrm{dA}_{31 \%} \mathrm{AX}$ material (data unavailable because the film was soft to be a free-standing film). Secondorder polynomial fit for tensile strain $\left(R^{2}=0.995\right)$ and second-order polynomial for $T_{\mathrm{g}}\left(R^{2}=0.99988\right)$. (b) Evolution of tensile strain and $T_{\mathrm{g}}$ against the molar substitution of $i$ PrGE-etherified dA-AX samples. (v)-(viii) $i \operatorname{PrGE}_{1.0} \mathrm{dA}_{19 \%} \mathrm{AX}, i \operatorname{PrGE}_{3.0} \mathrm{dA}_{19 \%} \mathrm{AX}_{2} i \operatorname{PrGE} 3.0 \mathrm{dA}_{31 \%} \mathrm{AX}$, and $i \operatorname{PrGE} E_{5.0} \mathrm{dA}_{31 \%} \mathrm{AX}$ second-order polynomial fit for tensile strain $\left(R^{2}=0.99416\right)$ and second-order polynomial fit for $T_{\mathrm{g}}\left(R^{2}=0.97871\right)$. The solid (green, for $\varepsilon_{\mathrm{b}}$ ) and dashed (blue, for $T_{\mathrm{g}}$ ) lines are used as the visual guide for the fit. Note that subzero endotherm calculated $T_{\mathrm{g}}$ values of BuGEetherified samples are used for plotting and curve fitting.

temperature of the former samples $\left(269^{\circ} \mathrm{C}\right)$ is higher than that of the latter $\left(261{ }^{\circ} \mathrm{C}\right)$.

Thermal stability of the BuGE-etherified di-alcohol AX (BuGE-dA-AX) samples decreases with the combined effect of an increase in oxidation level and in mole equivalence of GE/ASU compared to their di-alcohol AX counterparts. It is reflected from the significant reduction in the onset decomposition temperature $\left(T_{\text {onset }}\right)$ (Table 3$)$. This trend also remains valid with $i$ PrGE-etherified di-alcohol $A X$ (iPrGE-dA-AX) samples, but the reduction is less pronounced. The lower thermal stability of BuGE-dA-AX samples occurs from the alkoxide side chains' ability to depolymerize back to epoxides. As the content of alkoxide side chains increases (Figure S1c), the depolymerization possibility increases and may speed up thermal decomposition. The chemical modifications of celluloses fibrils ${ }^{61}$ and arabinoxylan $^{34,36}$ decreased the thermal decomposition temperature. The endset decomposition temperatures $\left(T_{\text {endset }}\right)$ of GE-dAAX samples (BuGE-dA-AX $320{ }^{\circ} \mathrm{C}$ and $i$ PrGE-dA-AX 316 ${ }^{\circ} \mathrm{C}$ ) are higher than those of dA-AX samples (301 and 311 ${ }^{\circ} \mathrm{C}$ ), indicating the wider decomposition temperature window (Table 3).
Mechanical Properties. The mechanical properties of the neat AX and GE-dA-AX samples were examined by the tensile test. Young's modulus, maximum tensile stress, and elongation at break data are presented in Table 3 and Figure S15. As expected, the materials with subzero $T_{\mathrm{g}}$, i.e., $\mathrm{BuGE}_{3.0} \mathrm{dA}_{19 \%} \mathrm{AX}$ and $\mathrm{BuGE}_{3.0} \mathrm{dA}_{31 \%} \mathrm{AX}$, are the most stretchable films with 244 $( \pm 42)$ and $267 \%( \pm 72)$ elongation at break $\left(\varepsilon_{\mathrm{b}}\right)$. The $\varepsilon_{\mathrm{b}}$ of $i$ PrGE-dA-AX samples can hardly reach up to $50 \%$ (Figure 5 ).

In a previous study, a maximum of $185 \%( \pm 32) \varepsilon_{\mathrm{b}}$ was achieved. ${ }^{34}$ Increased stretchability indicates stronger intramolecular interactions within a polymer chain but weak intermolecular interactions between neighboring chains because of the scission of intermolecular $\mathrm{H}$ bonding within the activated AX ethers after introducing glycidyl ethers. The presence of oxygen atoms in alkoxide chains and longer alkoxide chains, respectively, result in stronger intramolecular interactions and weak intermolecular interactions in the case of activated $\mathrm{AX}$ BuGE ethers as compared to the activated $\mathrm{AX}$ $i$ PrGE ethers. The former factor helps in coordinating neighboring $\mathrm{H}$ atoms, and the latter factor creates more space between the chains. This explains the higher strain at break (i.e., stretchability) for the activated AX BuGE ethers compared to those of the activated AX $i$ PrGE ethers. Young's 

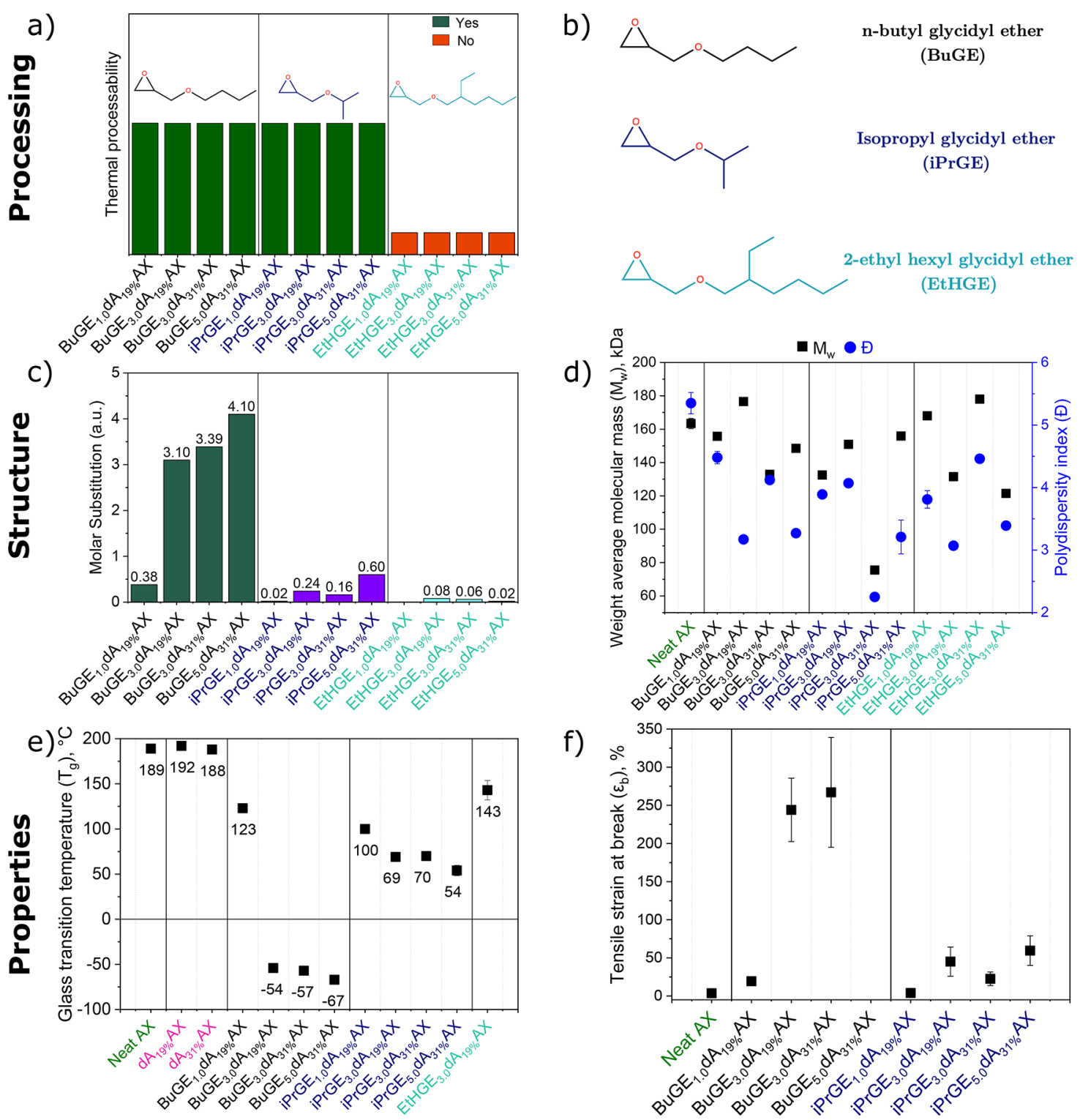

Figure 7. (a) Thermal processability of the activated AX ethers, (b) structures of the etherification agents, (c) molar substitution (NMRdetermined) of the activated AX ethers, (d) weight-average molecular masses and polydispersity indices of the neat AX and the activated AX ethers, (e) glass-transition temperatures $\left(T_{\mathrm{g}}\right)$ of the activated AX ethers, and (f) tensile strain at break of the neat AX and the activated AX ethers. These plots were grouped to better compare and find out the relationship among them. Note that $\mathrm{BuGE}_{5,0} \mathrm{dA}_{31 \%} \mathrm{AX}$ in Figure $7 \mathrm{f}$ does not have a tensile strain value because the film was too soft to be free standing.

modulus $(E)$ and tensile stress $\left(\sigma_{t}\right)$ of the neat $\mathrm{AX}$ and $\mathrm{BuGE}_{1.0} \mathrm{dA}_{19 \%} \mathrm{AX}$ are comparable. However, the $E$ and $\sigma_{\mathrm{t}}$ of $\mathrm{BuGE}_{3.0} \mathrm{dA}_{19 \%} \mathrm{AX}$ and $\mathrm{BuGE}_{3.0} \mathrm{dA}_{31 \%} \mathrm{AX}$ samples were very low at room temperature, i.e., above their subzero $T_{\mathrm{g}}$ (Table 3 ). It is worth noting that augmentation in tensile strain comes with a loss in tensile stress and Young's modulus. Strength and toughness properties are mutually exclusive, resulting in a trade off between these, and this poses a challenge in designing materials. ${ }^{62,63}$

Structure-Property-Processing Correlation. The qualitative structure-property relationship of the different samples, i.e., the relationship between molar substitution, tensile strain, and glass-transition temperature, was evaluated and is shown in Figure 6. There is an increasing trend with the final leveled-off region for tensile strain $\left(\varepsilon_{\mathrm{b}}\right)$ and a decreasing trend with the final leveled-off region for $T_{g}$, regarding the molar substitutions of etherification agents regardless of the type of coupled etherification agents (BuGE-etherified samples-Figure $6 \mathrm{a}$ and $i$ PrGE-etherified samples-Figure $6 \mathrm{~b})$. The longer alkoxide chain of BuGE and the shorter and branched chain of $i$ PrGE have contributed to higher and lower elongation at break, i.e., stretchability, respectively, as shown in the Mechanical Properties section. However, the curve-fitting data of BuGE-etherified samples $\left(R^{2}=0.995\right.$ and 0.99988 for $\varepsilon_{\mathrm{b}}$ and $T_{\mathrm{g}}$, respectively) is better than those of $i \operatorname{PrGE}$-etherified samples $\left(R^{2}=0.99416\right.$ and 0.97871 for $\varepsilon_{\mathrm{b}}$ and $\left.T_{\mathrm{g}}\right)$. Note that the MS, $\varepsilon_{\mathrm{b}}$, and $T_{\mathrm{g}}$ values of $i$ PrGE-etherified samples are lower than those of BuGE-etherified samples, though the curvefitting shape is similar.

Figure 7a,c shows structure-processing relationship and shows introducing etherification agents in the dA-AX samples, enabling thermal processing by compression molding, thus acting as internal thermal plasticizers, as shown by MS values (Table 2 and Figure 7c). Introducing BuGE and $i$ PrGE in the 
activated AXs enabled thermal processing. It also supports the fact that it is not possible to enable thermal processing without a covalently bonded internal thermal plasticizer as was shown for EtHGE. It is worth noting that the $T_{\mathrm{g}}$ of $\mathrm{EtHGE}_{3.0} \mathrm{dA}_{19 \%} \mathrm{AX}$ decreases to 143 from $180{ }^{\circ} \mathrm{C}$ compared to its starting material, i.e., $\mathrm{dA}_{31 \%} \mathrm{AX}$, however, does not enable thermal processability (Figure $7 \mathrm{a}, \mathrm{c}, \mathrm{e}$ ). This result has to do with the degradation/chemical modification of the polymer during the etherification reactions. In addition, $T_{g}$ is measured as the inflection point of the endotherm part (Figure S13a'). In fact, $T_{\mathrm{g}}$ is normally spread over a range of temperatures. Conversely, it was argued that reducing $T_{\mathrm{g}}$ may render arabinoxylan and xylan capable of thermal processing. ${ }^{32,36}$ Our results $\left(T_{g}\right.$, molar substitution, and IR data) showing lower $T_{\mathrm{g}}$ through chemical modification with elongating side chains in AX may enable thermal processing.

Figures $7 \mathrm{a}$ and S16 reveal the relation between thermomechanical properties (degradation and glass-transition temperature) and thermal processing. It becomes clear that

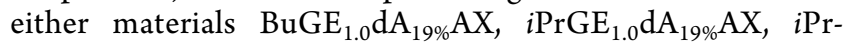
$\mathrm{GE}_{3.0} \mathrm{dA}_{19 \%} \mathrm{AX}, i \operatorname{PrGE}_{3.0} \mathrm{dA}_{31 \%} \mathrm{AX}$, and $i \mathrm{PrGE}_{5.0} \mathrm{dA}_{31 \%} \mathrm{AX}$ with a minimum $50{ }^{\circ} \mathrm{C}$ temperature difference between the onset of degradation temperature and $T_{\mathrm{g}}$ or materials $\mathrm{BuGE}_{3.0} \mathrm{dA}_{19 \%} \mathrm{AX}$, $\mathrm{BuGE}_{3.0} \mathrm{dA}_{31 \%} \mathrm{AX}$, and $\mathrm{BuGE}_{5.0} \mathrm{dA}_{31 \%} \mathrm{AX}$ having two endotherms (thus two $T_{\mathrm{g}}$ values) render thermal processability (Figure S16). One more important outcome of this work is that stretchability of $\mathrm{BuGE}_{3.0} \mathrm{dA}_{19 \%} \mathrm{AX}$ and $\mathrm{BuGE}_{3.0} \mathrm{dA}_{31 \%} \mathrm{AX}$ films $\left(\varepsilon_{\mathrm{b}}=244 \%( \pm 42)\right.$ and $267 \%( \pm 72)$; Table 3 and Figure $7 \mathrm{f})$ apparently correlates to the subzero $T_{\mathrm{g}}$ 's in these materials (Table 3 and Figure 7e).

\section{CONCLUSIONS}

Exploring new ways to achieve thermoplasticity for polysaccharide-based polymers by chemical modification and understanding the relationship among their structure, processing, and properties are crucial both for their current application areas such as packaging and films and for their new application areas, namely, substrates for stretchable electronics. Our results show that the successful introduction of $n$-butyl (BuGE) and isopropyl (iPrGE) glycidyl ethers in the activated arabinoxylans render thermal processability via compression molding. The thermal processability got enabled for all combinations of activation (periodate oxidation and reduction) and etherification reaction conditions for $n$-butyl (BuGE) and isopropyl (iPrGE) glycidyl ethers. It was also established that both the structure and composition of the native AX and modified AX, and the structure and chemical and physical properties of the etherification agents have strong implications on the thermal processability and final properties of the obtained materials. In the case of $\mathrm{BuGE}_{3.0} \mathrm{dA}_{19 \%} \mathrm{AX}$ and $\mathrm{BuGE}_{3.0} \mathrm{dA}_{31 \%} \mathrm{AX}$ films with longer alkoxide chains and a higher level of molar substitution, two endotherms $\left(1 T_{\mathrm{g}} 160{ }^{\circ} \mathrm{C}\right.$ and another subzero $\left.T_{\mathrm{g}}\right)$ in DSC curves are observed, giving $244( \pm 41.6)$ and $267 \%( \pm 72)$ elongation. In contrast, $i \operatorname{PrGE}_{1.0} \mathrm{dA}_{19 \%} \mathrm{AX}, i \operatorname{PrGE}_{3.0} \mathrm{dA}_{19 \%} \mathrm{AX}$, $i \operatorname{PrGE}_{3.0} \mathrm{dA}_{31 \%} \mathrm{AX}$, and $i \operatorname{PrGE}_{5.0} \mathrm{dA}_{31 \%} \mathrm{AX}$ films exhibit a single $T_{\mathrm{g}}$ value between 50 and $100{ }^{\circ} \mathrm{C}$ and have a maximum $59.5 \%$ strain at break.

The findings of this study contribute to the continued development of chemical modification strategies to enable thermoplasticity and processability via commercial polymer techniques and provide new insights into the structureprocessing-property relationship of the AX-based thermoplastic materials. The findings are pertinent for the material scientists working on polysaccharide-based materials for potential applications in packaging and substrates for stretchable electronics. We propose to use dynamic mechanical analysis and broadband dielectric spectroscopy to better understand the molecular mobility of the materials, i.e., main and secondary relaxations.

\section{ASSOCIATED CONTENT}

\section{SI Supporting Information}

The Supporting Information is available free of charge at https://pubs.acs.org/doi/10.1021/acsabm.0c01550.

Arabinoxylan extraction; structural, chemical, and physical properties of the etherification agents; sample coding; product (activated AX ether) yield and film fabrication techniques used; oxidation level measurement; glycidyl ether substitution; carbohydrate composition; molar mass distribution determined by gel permeation chromatography in $\mathrm{DMSO} / \mathrm{LiBr}$; ATRFTIR spectra; representative ${ }^{1} \mathrm{H}$ NMR spectra; integrals of $\alpha, \beta$, and methyl proton peaks of activated AX ethers and their ranges used for molar substitution; DSC heating-cooling-heating cycles; thermogravimetric and derivative thermogravimetric thermograms; tensile data and glass transition temperature ( $\mathrm{Tg}$ ) and degradation temperature $(\mathrm{Td})(\mathrm{PDF})$

\section{AUTHOR INFORMATION}

\section{Corresponding Authors}

Parveen Kumar Deralia - Department of Chemistry and Chemical Engineering, Chalmers University of Technology, SE-412 96 Gothenburg, Sweden; 이이이.org/0000-0002-

1014-5524; Email: deralia@chalmers.se, deralia.parveen@ gmail.com

Gunnar Westman - Department of Chemistry and Chemical Engineering, Chalmers University of Technology, SE-412 96 Gothenburg, Sweden; Email: westman@chalmers.se

\section{Authors}

Aline Maire du Poset - Department of Chemistry and Chemical Engineering, Chalmers University of Technology, SE-412 96 Gothenburg, Sweden

Anja Lund - Department of Chemistry and Chemical Engineering, Chalmers University of Technology, SE-412 96 Gothenburg, Sweden

Anette Larsson - Department of Chemistry and Chemical Engineering, Chalmers University of Technology, SE-412 96 Gothenburg, Sweden; (1) orcid.org/0000-0002-6119-8423

Anna Ström - Department of Chemistry and Chemical Engineering, Chalmers University of Technology, SE-412 96 Gothenburg, Sweden; (1) orcid.org/0000-0002-9743-1514

Complete contact information is available at:

https://pubs.acs.org/10.1021/acsabm.0c01550

\section{Notes}

The authors declare no competing financial interest.

\section{ACKNOWLEDGMENTS}

This work was supported by the Lantmännen Research Foundation (Project No. 2017/H017). The authors are grateful to Professor Hans Theliander and Associate Professor Merima Hasani at Forest Products and Chemical Engineering at Chalmers University of Technology, Gothenburg, Sweden 
for granting access to the HPLC and GPC instruments. The authors also thank Dr. Amit Kumar Sonker in our lab for the help with DSC.

\section{REFERENCES}

(1) Schooneveld-Bergmans, M. E. F.; Beldman, G.; Voragen, A. G. J. Structural Features of (Glucurono)Arabinoxylans Extracted from Wheat Bran by Barium Hydroxide. J. Cereal Sci. 1999, 29, 63-75.

(2) Izydorczyk, M. S.; Dexter, J. E. Barley $\beta$-Glucans and Arabinoxylans: Molecular Structure, Physicochemical Properties, and Uses in Food Products-a Review. Food Res. Int. 2008, 41, 850868.

(3) Srinivasan, M.; Sudheer, A. R.; Menon, V. P. Ferulic Acid: Therapeutic Potential through Its Antioxidant Property. J. Clin. Biochem. Nutr. 2007, 40, 92-100.

(4) Mikkonen, K. S.; Tenkanen, M.; Cooke, P.; Xu, C.; Rita, H.; Willför, S.; Holmbom, B.; Hicks, K. B.; Yadav, M. P. Mannans as Stabilizers of Oil-in-Water Beverage Emulsions. LWT-Food Sci. Technol. 2009, 42, 849-855.

(5) Lima, D. U.; Oliveira, R. C.; Buckeridge, M. S. Seed Storage Hemicelluloses as Wet-End Additives in Papermaking. Carbohydr. Polym. 2003, 52, 367-373.

(6) Wang, L.; Lou, Z.; Wang, K.; Zhao, S.; Yu, P.; Wei, W.; Wang, D.; Han, W.; Jiang, K.; Shen, G. Biocompatible and Biodegradable Functional Polysaccharides for Flexible Humidity Sensors. Research 2020, 2020, 1-11.

(7) Fu, Q.; Chen, Y.; Sorieul, M. Wood-Based Flexible Electronics. ACS Nano 2020, 14, 3528-3538.

(8) Hoeng, F.; Denneulin, A.; Bras, J. Use of Nanocellulose in Printed Electronics: A Review. Nanoscale 2016, 8, 13131-13154.

(9) Farhat, W.; Venditti, R.; Becquart, F.; Ayoub, A.; Majesté, J.-C.; Taha, M.; Mignard, N. Synthesis and Characterization of Thermoresponsive Xylan Networks by Diels-Alder Reaction. ACS Appl. Polym. Mater. 2019, 1, 856-866.

(10) Szcześniak, L.; Rachocki, A.; Tritt-Goc, J. Glass Transition Temperature and Thermal Decomposition of Cellulose Powder. Cellulose 2008, 15, 445-451.

(11) Teramoto, Y. Functional Thermoplastic Materials from Derivatives of Cellulose and Related Structural Polysaccharides. Molecules 2015, 20, 5487-5527.

(12) Enomoto-Rogers, Y.; Ohmomo, Y.; Takemura, A.; Iwata, T. Syntheses of Glucomannan Esters and Their Thermal and Mechanical Properties. Carbohydr. Polym. 2014, 101, 592-599.

(13) Mekonnen, T.; Mussone, P.; Khalil, H.; Bressler, D. Progress in Bio-Based Plastics and Plasticizing Modifications. J. Mater. Chem. A 2013, 1, 13379-13398.

(14) De Groote, P.; Devaux, J.; Godard, P. Effect of Benzenesulfonamide Plasticizers on the Glass-Transition Temperature of Semicrystalline Polydodecamide. J. Polym. Sci., Part B: Polym. Phys. 2002, 40, 2208-2218.

(15) Avérous, L.; Pollet, E. Nanobiocomposites Based on Plasticized Starch. Starch Polym. 2014, 211-239.

(16) Mathew, A. P.; Dufresne, A. Morphological Investigation of Nanocomposites from Sorbitol Plasticized Starch and Tunicin Whiskers. Biomacromolecules 2002, 3, 609-617.

(17) Zepnik, S.; Kabasci, S.; Kopitzky, R.; Radusch, H.-J.; Wodke, T. Extensional Flow Properties of Externally Plasticized Cellulose Acetate: Influence of Plasticizer Content. Polymers 2013, 5, 873-889.

(18) Li, H.; Huneault, M. A. Comparison of Sorbitol and Glycerol as Plasticizers for Thermoplastic Starch in TPS/PLA Blends. J. Appl. Polym. Sci. 2010, 119, 2439-2448.

(19) Chaudhary, A. L.; Torley, P. J.; Halley, P. J.; McCaffery, N.; Chaudhary, D. S. Amylose Content and Chemical Modification Effects on Thermoplastic Starch from Maize - Processing and Characterisation Using Conventional Polymer Equipment. Carbohydr. Polym. 2009, 78, 917-925.

(20) Chaudhary, A. L.; Miler, M.; Torley, P. J.; Sopade, P. A.; Halley, P. J. Amylose Content and Chemical Modification Effects on the
Extrusion of Thermoplastic Starch from Maize. Carbohydr. Polym. 2008, 74, 907-913.

(21) Zamudio-Flores, P. B.; Torres, A. V.; Salgado-Delgado, R.; Bello-Pérez, L. A. Influence of the Oxidation and Acetylation of Banana Starch on the Mechanical and Water Barrier Properties of Modified Starch and Modified Starch/Chitosan Blend Films. J. Appl. Polym. Sci. 2010, 115, 991-998.

(22) Volkert, B.; Lehmann, A.; Greco, T.; Nejad, M. H. A Comparison of Different Synthesis Routes for Starch Acetates and the Resulting Mechanical Properties. Carbohydr. Polym. 2010, 79, 571-577.

(23) Reddy, N.; Yang, Y. Preparation and Properties of Starch Acetate Fibers for Potential Tissue Engineering Applications. Biotechnol. Bioeng. 2009, 103, 1016-1022.

(24) Bhattacharya, A.; Misra, B. N. Grafting: A Versatile Means to Modify Polymers: Techniques, Factors and Applications. Prog. Polym. Sci. 2004, 29, 767-814.

(25) Xi, D.; Yang, C.; Liu, X.; Chen, M.; Sun, C.; Xu, Y. Graft Polymerization of Styrene on Soy Protein Isolate. J. Appl. Polym. Sci. 2005, 98, 1457-1461.

(26) Quintana, R.; Persenaire, O.; Bonnaud, L.; Dubois, P. Recent Advances in (Reactive) Melt Processing of Cellulose Acetate and Related Biodegradable Bio-Compositions. Polym. Chem. 2012, 3, 591-595.

(27) Stiubianu, G.; Nicolescu, A.; Nistor, A.; Cazacu, M.; Varganici, C.; Simionescu, B. C. Chemical Modification of Cellulose Acetate by Allylation and Crosslinking with Siloxane Derivatives. Polym. Int. 2012, 61, 1115-1126.

(28) Biermann, C. J.; Chung, J. B.; Narayan, R. Grafting of Polystyrene onto Cellulose Acetate by Nucleophilic Displacement of Mesylate Groups Using the Polystyrylcarboxylate Anion. Macromolecules 1987, 20, 954-957.

(29) Ren, J. L.; Sun, R. C.; Liu, C. F.; Cao, Z. N.; Luo, W. Acetylation of Wheat Straw Hemicelluloses in Ionic Liquid Using Iodine as a Catalyst. Carbohydr. Polym. 2007, 70, 406-414.

(30) Biswas, A.; Shogren, R. L.; Willett, J. L. Solvent-Free Process to Esterify Polysaccharides. Biomacromolecules 2005, 6, 1843-1845.

(31) Kristiansen, K. A.; Potthast, A.; Christensen, B. E. Periodate Oxidation of Polysaccharides for Modification of Chemical and Physical Properties. Carbohydr. Res. 2010, 345, 1264-1271.

(32) Stepan, A. M.; Höije, A.; Schols, H. A.; De Waard, P.; Gatenholm, P. Arabinose Content of Arabinoxylans Contributes to Flexibility of Acetylated Arabinoxylan Films. J. Appl. Polym. Sci. 2012, $125,2348-2355$.

(33) Jain, R. K.; Sjöstedt, M.; Glasser, W. G. Thermoplastic Xylan Derivatives with Propylene Oxide. Cellulose 2000, 7, 319-336.

(34) Börjesson, M.; Westman, G.; Larsson, A.; Ström, A. Thermoplastic and Flexible Films from Arabinoxylan. ACS Appl. Polym. Mater. 2019, 1, 1443-1450.

(35) Nypelö, T.; Laine, C.; Aoki, M.; Tammelin, T.; Henniges, U. Etherification of Wood-Based Hemicelluloses for Interfacial Activity. Biomacromolecules 2016, 17, 1894-1901.

(36) Börjesson, M.; Larsson, A.; Westman, G.; Ström, A. Periodate Oxidation of Xylan-Based Hemicelluloses and Its Effect on Their Thermal Properties. Carbohydr. Polym. 2018, 202, 280-287.

(37) Svärd, A.; Brännvall, E.; Edlund, U. Modified and Thermoplastic Rapeseed Straw Xylan: A Renewable Additive in PCL Biocomposites. Ind. Crops Prod. 2018, 119, 73-82.

(38) Farhat, W.; Venditti, R.; Ayoub, A.; Prochazka, F.; Fernándezde-Alba, C.; Mignard, N.; Taha, M.; Becquart, F. Towards Thermoplastic Hemicellulose: Chemistry and Characteristics of Poly-( $\varepsilon$-Caprolactone) Grafting onto Hemicellulose Backbones. Mater. Des. 2018, 153, 298-307.

(39) Zhang, X.; Chen, M.; Liu, C.; Zhang, A.; Sun, R. Ring-Opening Graft Polymerization of Propylene Carbonate onto Xylan in an Ionic Liquid. Molecules 2015, 20, 6033-6047.

(40) Zerroukhi, A.; Jeanmaire, T.; Raveyre, C.; Ainser, A. Synthesis and Characterization of Hydrophobically Modified Starch by Ring 
Opening Polymerization Using Imidazole as Catalyst. Starch/Stärke 2012, 64, 613-620.

(41) Miyamae, Y.; Kanazawa, A.; Tamaso, K.-i.; Morino, K.; Ogawa, R.; Aoshima, S. The Influence of the Substituents of Oxiranes on Copolymerization with Vinyl Ethers via Concurrent Cationic VinylAddition and Ring-Opening Mechanisms. Polym. Chem. 2018, 9, 404-413.

(42) Sluiter, A.; Hames, B.; Ruiz, R.; Scarlata, C.; Sluiter, J.; Templeton, D. Determination of Structural Carbohydrates and Lignin in Biomass; NREL/TP-510-42618, National Renewable Energy Laboratory, 2011.

(43) Börjesson, M.; Härdelin, L.; Nylander, F.; Karlsson, K.; Larsson, A.; Westman, G. Arabinoxylan and Nanocellulose from a Kilogram-Scale Extraction of Barley Husk. BioResources 2018, 13, 6201-6220.

(44) Siller, M.; Amer, H.; Bacher, M.; Roggenstein, W.; Rosenau, T.; Potthast, A. Effects of Periodate Oxidation on Cellulose Polymorphs. Cellulose 2015, 22, 2245-2261.

(45) Amer, H.; Nypelö, T.; Sulaeva, I.; Bacher, M.; Henniges, U.; Potthast, A.; Rosenau, T. Synthesis and Characterization of PeriodateOxidized Polysaccharides: Dialdehyde Xylan (DAX). Biomacromolecules 2016, 17, 2972-2980.

(46) Maekawa, E.; Kosaki, T.; Koshijima, T. Periodate Oxidation of Mercerized Cellulose and Regenerated Cellulose. Wood Res. 1986, 73, 44-49.

(47) Wang, J.; Somasundaran, P. Mechanisms of Ethyl(Hydroxyethyl) Cellulose-Solid Interaction: Influence of Hydrophobic Modification. J. Colloid Interface Sci. 2006, 293, 322-332.

(48) Coates, J. Interpretation of Infrared Spectra, A Practical Approach. Encycl. Anal. Chem. 2006, DOI: 10.1002/ 9780470027318.a5606, In.

(49) Kurt, A.; Kahyaoglu, T. Characterization of a New Biodegradable Edible Film Made from Salep Glucomannan. Carbohydr. Polym. 2014, 104, 50-58.

(50) Miyachi, K.; Sato, S.; Kakuchi, T.; Isono, T.; Satoh, T.; Satoh, Y. Design and Synthesis of Thermoresponsive Aliphatic Polyethers with a Tunable Phase Transition Temperature. Polym. Chem. 2017, 8, 5698-5707.

(51) Pitkänen, L.; Virkki, L.; Tenkanen, M.; Tuomainen, P. Comprehensive Multidetector HPSEC Study on Solution Properties of Cereal Arabinoxylans in Aqueous and DMSO Solutions. Biomacromolecules 2009, 10, 1962-1969.

(52) Kucherov, F. A.; Gordeev, E. G.; Kashin, A. S.; Ananikov, V. P. Three-Dimensional Printing with Biomass-Derived PEF for CarbonNeutral Manufacturing. Angew. Chem., Int. Ed. 2017, 56, 1593115935.

(53) Park, S. A.; Jeon, H.; Kim, H.; Shin, S. H.; Choy, S.; Hwang, D. S.; Koo, J. M.; Jegal, J.; Hwang, S. Y.; Park, J.; Oh, D. X. Sustainable and Recyclable Super Engineering Thermoplastic from Biorenewable Monomer. Nat. Commun. 2019, 10, No. 2601.

(54) Sharma, A.; Pan, X.; Bjuggren, J. M.; Gedefaw, D.; Xu, X.; Kroon, R.; Wang, E.; Campbell, J. A.; Lewis, D. A.; Andersson, M. R. Probing the Relationship between Molecular Structures, Thermal Transitions, and Morphology in Polymer Semiconductors Using a Woven Glass-Mesh-Based DMTA Technique. Chem. Mater. 2019, 31, 6740-6749.

(55) Martello, M. T.; Schneiderman, D. K.; Hillmyer, M. A. Synthesis and Melt Processing of Sustainable Poly $(\varepsilon$-Decalactone)Block-Poly(Lactide) Multiblock Thermoplastic Elastomers. ACS Sustainable Chem. Eng. 2014, 2, 2519-2526.

(56) Zhang, J.; Deubler, R.; Hartlieb, M.; Martin, L.; Tanaka, J.; Patyukova, E.; Topham, P. D.; Schacher, F. H.; Perrier, S. Evolution of Microphase Separation with Variations of Segments of SequenceControlled Multiblock Copolymers. Macromolecules 2017, 50, 73807387.

(57) Chen, Z.; Zhang, J. J.; Xiao, P.; Tian, W.; Zhang, J. J. Novel Thermoplastic Cellulose Esters Containing Bulky Moieties and Soft Segments. ACS Sustainable Chem. Eng. 2018, 6, 4931-4939.
(58) Saito, T.; Brown, R. H.; Hunt, M. A.; Pickel, D. L.; Pickel, J. M.; Messman, J. M.; Baker, F. S.; Keller, M.; Naskar, A. K. Turning Renewable Resources into Value-Added Polymer: Development of Lignin-Based Thermoplastic. Green Chem. 2012, 14, 3295-3303.

(59) Saito, T.; Perkins, J. H.; Jackson, D. C.; Trammel, N. E.; Hunt, M. A.; Naskar, A. K. Development of Lignin-Based Polyurethane Thermoplastics. RSC Adv. 2013, 3, 21832-21840.

(60) Gregory, G. L.; Sulley, G. S.; Carrodeguas, L. P.; Chen, T. T. D.; Santmarti, A.; Terrill, N. J.; Lee, K. Y.; Williams, C. K. Triblock Polyester Thermoplastic Elastomers with Semi-Aromatic Polymer End Blocks by Ring-Opening Copolymerization. Chem. Sci. 2020, 11, 6567-6581.

(61) Fukuzumi, H.; Saito, T.; Iwata, T.; Kumamoto, Y.; Isogai, A. Transparent and High Gas Barrier Films of Cellulose Nanofibers Prepared by TEMPO-Mediated Oxidation. Biomacromolecules 2009, $10,162-165$.

(62) Ritchie, R. O. The Conflicts between Strength and Toughness. Nat. Mater. 2011, 10, 817-822.

(63) Basheer, B. V.; George, J. J.; Siengchin, S.; Parameswaranpillai, J. Polymer Grafted Carbon Nanotubes-Synthesis, Properties, and Applications: A Review. Nano-Struct. Nano-Objects 2020, 22, No. 100429. 